\title{
Simulating the impact of urban development pathways on the local climate: A scenario-based analysis in the greater Dublin region, Ireland
}

\author{
P.J. Alexander ${ }^{\mathrm{a}, *}$, R. Fealy ${ }^{\mathrm{b}}$, G.M. Mills ${ }^{\mathrm{c}}$ \\ a Irish Climate Analysis $\mathcal{E}$ Research Units, National University of Ireland, Maynooth, County Kildare, Ireland \\ ${ }^{\mathrm{b}}$ Department of Geography, National University of Ireland, Maynooth, County Kildare, Ireland \\ ' School of Geography, Planning \& Environmental Policy, University College Dublin, Dublin 4, Ireland
}

\section{H I G H L I G H T S}

- The impact of different future development pathways on local climate are simulated.

- Sprawling scenarios increased sensible/stored heat across $7.7-14.9 \%$ of the domain.

- Greening rooftops resulted in the lowering the impact on local scale climate.

\section{A R T I C L E I N F O}

\section{Article history:}

Received 8 August 2015

Received in revised form 2 February 2016

Accepted 4 February 2016

Available online 27 April 2016

\section{Keywords:}

Neighbourhood climate

Urban planning

SUEWS modelling

Surface energy balance

Low impact development

Local climate zones

\begin{abstract}
A B S T R A C T
In this study, the impact of different urban development scenarios on neighbourhood climate are examined. The investigation considers the relative impact differing policy/planning choices will have on the local-scale climate across a city during a typical climatological year (TCY). The aim is to demonstrate a modelling approach which couples a climate-based land classification and simple urban climate model and how this can be used to examine the impact differing urban forms and design strategies have on neighbourhood scale partitioning of energy and resulting consequences. Utilising the Surface Urban Energy and Water Balance (SUEWS) model (Järvi et al., 2011) hourly fluxes of sensible, latent and stored heat are simulated for an entire year under four different urban development scenarios. The land cover scenarios are based on those obtained by the MOLAND model for 2026 (Brennan et al., 2009) in our case study city Dublin (Ireland). MOLAND LULC are translated into local climate zones (Stewart and Oke, 2012) for examination. Subsequently, the types of building forms, vegetation type and coverage are modified based on realistic examples currently found across Dublin city. Our results focused on 2 principle aspects: the seasonality of energy partitioning with respect to vegetation and average diurnal partitioning of energy. Our analysis illustrates that compact scenarios are suitable form of future urban development in terms of reducing the spatial impact on the existing surface energy budget in Dublin. Design interventions which maintain the level of vegetation at a ratio $\geq 9: 16$ to artificial surfaces reduces the impact.
\end{abstract}

(c) 2016 Elsevier B.V. All rights reserved.

\section{Introduction}

Globally, city planners face significant pressures to accommodate a rapidly growing urban population. In the past 60 years, the urban population has increased by 3.154 billion and more than $50 \%$

\footnotetext{
* Corresponding author at: Irish Climate Analysis \& Research Units, Maynooth University, Room 1.8, Laraghbryan House, North Campus, Maynooth, County Kildare, Ireland.

E-mail addresses: paul.alexander@nuim.ie, paul.j.alexander@outlook.com (P.J. Alexander), rowan.fealy@nuim.ie (R. Fealy), gerald.mills@ucd.ie (G.M. Mills).
}

of the global population are now urban; by 2050 , it is projected that this proportion will exceed $66 \%$ (UN, 2014). Urban areas are a focus of human activity, energy consumption and greenhouse gas emissions and consequently are major drivers of global climate change; moreover, their locations at low altitude, along rivers and close to coasts exposes them to hazards (such as coastal flooding) that are likely to be exacerbated in under various climate change scenarios (IPCC, 2014). Urban areas also modify the local climate profoundly, producing well known climatic phenomena such as the urban heat island (UHI) (Karl, Diaz, \& Kukla, 1988; Patz, Campbell-Lendrum, Holloway, \& Foley, 2005), $\mathrm{CO}_{2}$ dome (Balling, Cerveny, \& Idso, 2001; Idsoa, Idso, \& Balling, 1998) and photochemical smog (Gray \& 
Finster, 2000; Moussiopoulos, Sahm, \& Kessler, 1995). These local to global climate effects are caused by two different, but related, aspects of cities. Urban form describes the surface cover (e.g. impervious fraction), the construction materials (e.g. asphalt) and the built geometry (e.g. the building dimensions and their juxtaposition). Urban function describes the activities in cities that require water, energy, materials etc.; the waste heat, vapour and materials are deposited into the atmosphere, hydrosphere and lithosphere. Urban form and function are strongly related so that, for example, more compact and densely occupied cities have lower per capita fuel use for transportation (Bramley \& Power, 2009; Breheny, 1991; Elkin, McLaren, \& Hillman, 1991; Mills, 2007).

As the world continues to urbanise, the global sustainable development challenges (and opportunities) will increasingly be concentrated in cities. Urban policies that address these must manage aspects of urban form and functions to mitigate (and adapt to) climate changes at different scales. This is especially true for economically developing countries where the rates of urbanisation are greatest and population growth outstrips the pace of planned development (Jorgenson \& Rice, 2010; Martine, McGranahan, Montgomery, \& Fernández-Castillia, 2008). The emerging layout of these fast-growing cities (e.g. urban extent, population and building density) will have long-term implications as once constructed, cities have proved difficult to alter. Incorporating climate knowledge into urban decision-making will be an important component in urban planning and creating more sustainable cities. In this respect, urban climate models (UCMs) are a potentially valuable tool for evaluating the impacts of different urban designs, land use, population densities and activities on the surface energy and water balances and the consequent effects on the local atmosphere and hydrology, respectively. Addressing local climate conditions (such as the UHI) can help reduce the contribution of individual cities to global climate change. In fact a variety of UCMs have been applied for precisely this purpose (see Table 1), yet there is little evidence that they have been used to inform spatial decision making (Eliasson, 2000; Hebbert \& Mackillop, 2013; Mills, 2008; Oke, 1984). By comparison, climatic considerations are routinely employed to assist building design (Brager \& de Dear, 1998; Givoni, 1992; Shaviv, 1984).

This 'knowledge circulation failure' (Hebbert \& MacKillop, 2013) has been attributed to many causes, including a mismatch between urban climate knowledge and planning/design concerns. For example, while climate research has examined the nocturnal UHI in considerable detail, architects and planners are most interested in daytime conditions when people occupy outdoor spaces and building energy demands are highest (Svensson \& Eliasson, 2002). To overcome this failure, existing research should be codified for planning use (Alcoforado, Andrade, Lopes, \& Vasconcelos, 2009; Mills et al., 2010) but also new research needs to be undertaken that meets urban planning needs (Gál \& Unger, 2009; Marland et al., 2003; Ward, 2003).

The use of land cover scenarios as one component of a planning support system is well established as a means of exploring factors which can be controlled by practitioners, and how they might be used to improve planning decisions and outcomes (Couclelis, 2005; Xiang \& Clarke, 2003). They are valuable tools for exploring the spatial impact of decisions on future land cover (Van de Voorde et al., 2016) and for testing particular policy priorities on future land use and land cover change (Veldkamp \& Fresco, 1997) or for exploring the impact of land cover on physical processes and risks, such as precipitation runoff (Niehoff, Fritsch, \& Bronstert, 2002). In this respect, while a scenario should be viewed as a possibility or projection rather than as a prediction, scenario-sets can be extremely useful for examining bio-physical impacts of urbanisation, and thus help reduce any inadvertent consequences associated with urban development when combined UCMs which have been evaluated in many circumstances and have demonstrated their potential for planning applications (Grimmond et al., 2010, 2011).

Previous research has demonstrated how available meteorological data can be used to run mid-to-complex urban energy balance models, which would allow the urban climate effect to be included in the planning process (Alexander, Mills, \& Fealy, 2015; Grimmond \& Oke, 2002). However, there has been little guidance on how to run UCMs using inputs from land cover scenarios, interpret their findings and integrate their projections to inform policy.

In this study, we demonstrate the utility of the surface urban energy and water balance scheme (SUEWS v.2013b) for evaluating the climatic impact of different scenarios of urban development. SUEWS is parameterised using values obtained from the Local Climate Zone (LCZ) scheme that describes neighbourhood types and is run using available meteorological data. This approach is applied to a case study city (Dublin, Ireland, $53.3^{\circ} \mathrm{N}, 6.3^{\circ} \mathrm{W}$ ) where the pathways for future growth are based on scenarios generated by the MOLAND model to 2026. These scenarios generate distinct land use and land cover (LULC) outcomes, which are translated into LCZ types to provide required parameter values. The output of the model illustrates the impacts of the different development pathways. Before discussing the methodology in detail, the potential value of the SUEWS model - linked with the LCZ scheme - for planning purposes is presented.

\section{Integrating LCZ and SUEWS to support planning decisions}

The LCZ scheme categorises landscapes into types based on their impact on the near-surface air temperature (Stewart \& Oke, 2012); it consists of 17 standard types, 10 of which are urban, 7 are non-urban (Fig. 1) but it can also accommodate mixed types. The scheme is properly applied at the local or neighbourhood-scale (areas greater than about $1 \mathrm{~km}^{2}$ ) where each type is differentiated from another based on a range of variables, such as, the fractional impervious cover, mean building height, building materials, sky view factor and anthropogenic heat generation. The net effect of these properties is to modulate the thermal response of the overlying atmosphere and create the urban heat island (UHI) phenomenon; this link has been validated in published work (Levlovics, Gál, \& Unger, 2013; Stewart, Oke, \& Krayenhoff, 2014). The value of the LCZ scheme extends beyond the UHI however, and could provide a platform for incorporating much urban climate knowledge into planning practice for a number of reasons:

- First, the UHI may be regarded as an indicator of urban climate effects generally, so mitigating it addresses other effects such as the lack of greenspaces and of available water. So a map of LCZ types in a city identifies where the urban effect is greatest.

- Second, LCZ types are designed to be culturally neutral (applicable internationally) and intuitive (user-friendly). As such they can clarify communication between climate scientists and planners e.g. Picone \& Campo (2015) see Fig. 2. Moreover, they can facilitate knowledge transfer between cities.

- Third, LCZs are useful for both observational and modelling studies of the local scale climate. A LCZ map of a city can be used to sample the urban landscape to measure climate variables and to gather more detailed information on surface characteristics to run UCMs. Even the current variables in the LCZ scheme correspond with the many UCM parameters.

Here, we link the LCZ scheme with the SUEWS climate model v.2013b (Järvi, Grimmond, \& Christen, 2011) to explore the impacts of urban development scenarios on neighbourhood scale climate. By integrating LCZ with SUEWS, urban form is accounted as either 
Built types

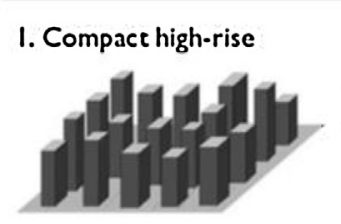

2. Compace midrise

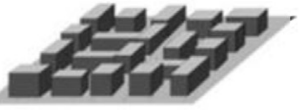

3. Compact low-rise

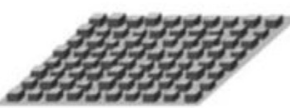

4. Open high-rise

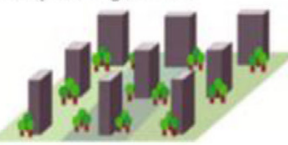

5. Open midrise

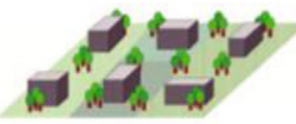

6. Open low-rise

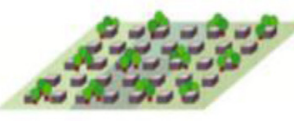

7. Lightweight low-rise

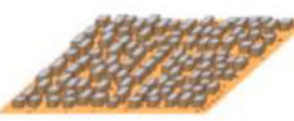

8. Large low-rise

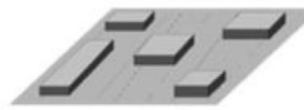

9. Sparsely built

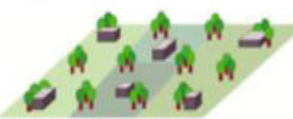

10. Heavy industry

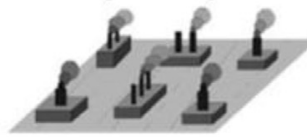

Definition

Dense mix of tall buildings to tens of stories. Few or no trees. Land cover mostly paved. Concrete, steel, stone, and glass construction materials.

Dense mix of midrise buildings (3-9 stories). Few or no trees. Land cover mostly paved. Stone, brick, tile, and concrete construction materials.

Dense mix of low-rise buildings ( $1-3$ stories). Few or no trees. Land cover mostly paved. Stone, brick, tile, and concrete construction materials.

Open arrangement of tall buildings to tens of stories. Abundance of pervious land cover (low plants, scattered trees). Concrete, steel, stone, and glass construction materials.

Open arrangement of midrise buildings (3-9 stories). Abundance of pervious land cover (low plants, scattered trees). Concrete, steel, stone, and glass construction materials.

Open arrangement of low-rise buildings ( $1-3$ stories). Abundance of pervious land cover (low plants, scattered trees). Wood, brick, stone, tile, and concrete construction materials.

Dense mix of single-story buildings. Few or no trees. Land cover mostly hard-packed. Lightweight construction materials (e.g., wood, thatch. corrugated metal).

Open arrangement of large low-rise buildings ( $1-3$ stories). Few or no trees. Land cover mostly paved. Steel, concrete, metal, and stone construction materials.

Sparse arrangement of small or medium-sized buildings in a natural setting. Abundance of pervious land cover (low plants, scattered trees).

Low-rise and midrise industrial structures (towers, tanks, stacks). Few or no trees. Land cover mostly paved or hard-packed. Metal, steel, and concrete construction materials.

Definition

\section{A. Dense trees

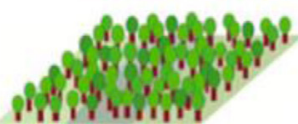

B. Scattered trees

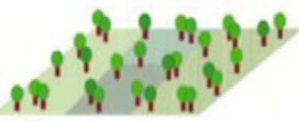

C. Bush, scrub

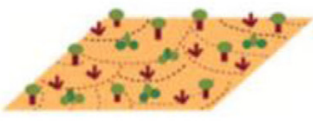

D. Low plants

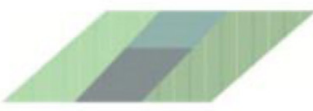

E. Bare rock or paved

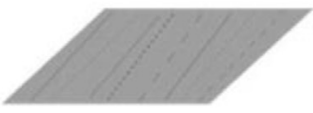

\section{F. Bare soil or sand}

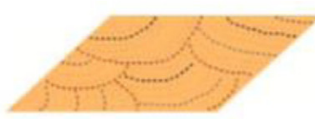

G. Water

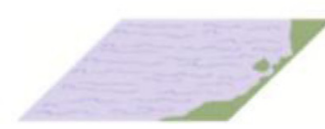

Large, open water bodies such as seas and lakes, or small bodies such as rivers, reservoirs, and lagoons.

\section{VARIABLE LAND COVER PROPERTIES}

Variable or ephemeral land cover properties that change significantly with synoptic weather patterns, agricultural practices. and/or seasonal cycles. b. bare trees

s. snow cover

d. dry ground

w. wet ground
Heavily wooded landscape of deciduous and/or evergreen trees. Land cover mostly pervious (low plants). Zone function is natural forest, tree cultivation, or urban park.

Lightly wooded landscape of deciduous and/or evergreen trees. Lover mostly pervious (low plants). Zone function is natura forest, tree cultivation, or urban park.

Open arrangement of bushes, shrubs, and short, woody trees. Land cover Zone function is natural scrubland or agriculture.

Feacureless landscape of grass or herbaceous plants/crops. Few or no trees. Zone function is natural grassland, agriculture, or urban park.

Featureless landscape of rock or paved cover. Few or no trees or plants. Zone function is natural desert (rock) or urban transportation.

Featureless landscape of soil or sand cover. Few or no trees or plants. Zone function is natural desert or agriculture.

Small Bowen ratio. Reduced albedo.

Fig. 1. Local climate zone scheme for universally describing neighbourhood morphology and thermal climate (Stewart and Oke, 2012). Each zone is defined on the basis of

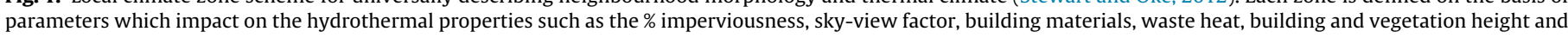
so forth. 
Table 1

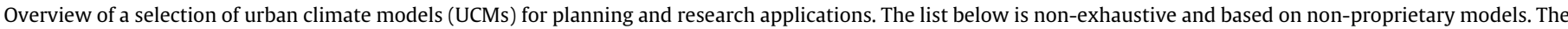
list also excludes building-scale energy models. Scale refers to the resolution of the model output, where $\mu=\mathrm{micro}(1-100 \mathrm{~m}) \alpha=\mathrm{local}(1-2 \mathrm{~km}) \beta=\mathrm{meso}(>2 \mathrm{~km}) \mathrm{scale}$.

\begin{tabular}{|c|c|c|c|}
\hline Model name & $\begin{array}{l}\text { Model } \\
\text { reference }\end{array}$ & Scale & Reviewed exemplar applications \\
\hline ENVI-met & Bruse (1999) & $\mu-\alpha$ & $\begin{array}{l}\text { Building form impacts on microclimate (Middel, Häb, Brazel, Martin, \& Guhathakurta) } \\
\text { Green-roof strategies and HTC (Peng and Jim, 2013) }\end{array}$ \\
\hline MITRAS & $\begin{array}{l}\text { Schlünzen et al. } \\
\text { (2003) }\end{array}$ & $\mu$ & $\begin{array}{l}\text { Wind flow patterns, dispersion (Schlünzen, Grawe, Bohnenstengel, Schlüter, \& } \\
\text { Koppmann) }\end{array}$ \\
\hline SOLWEIG & $\begin{array}{l}\text { Lindberg et al. } \\
\text { (2008) }\end{array}$ & $\mu-\alpha$ & $\begin{array}{l}\text { Vegetation and building form impacts on shadow patterns, mean radiant } \\
\text { temperatures (Lindberg and Grimmond, 2011) Impact of urban planning on HTC } \\
\text { (Goldberg, Kurbjuhn, \& Bernhofer, 2013) }\end{array}$ \\
\hline SLUCM (WRF) & $\begin{array}{l}\text { Kusaka et al. } \\
\text { (2001) }\end{array}$ & $\alpha-\beta$ & $\begin{array}{l}\text { Simulating urban expansion impacts on temperature, wind speed and surface ozone } \\
\text { concentrations (Wang, Lin, Yang, Deng, \& Lin) Land-Sea breeze and UHI development } \\
\text { (Lin et al., 2008) }\end{array}$ \\
\hline SUEWS & $\begin{array}{l}\text { Järvi et al. } \\
\text { (2011) }\end{array}$ & $\alpha-\beta$ & BRIDGE project, ensembles modelling for urban hydrology (Chrysoulakis et al., 2013) \\
\hline TUF-3D & $\begin{array}{l}\text { Krayenhoff and } \\
\text { Voogt, (2007) }\end{array}$ & $\mu$ & Use of artificial turf to reduce surface and air temperature (Yaghoobian et al., 2010) \\
\hline TEB & Masson (2000) & $\mu-\beta$ & $\begin{array}{l}\text { Impact of climate change on temperature and cooling demands in Paris (Lemonsu, } \\
\text { Kounkou-Arnaud, Desplat, Salagnac, \& Masson) }\end{array}$ \\
\hline
\end{tabular}

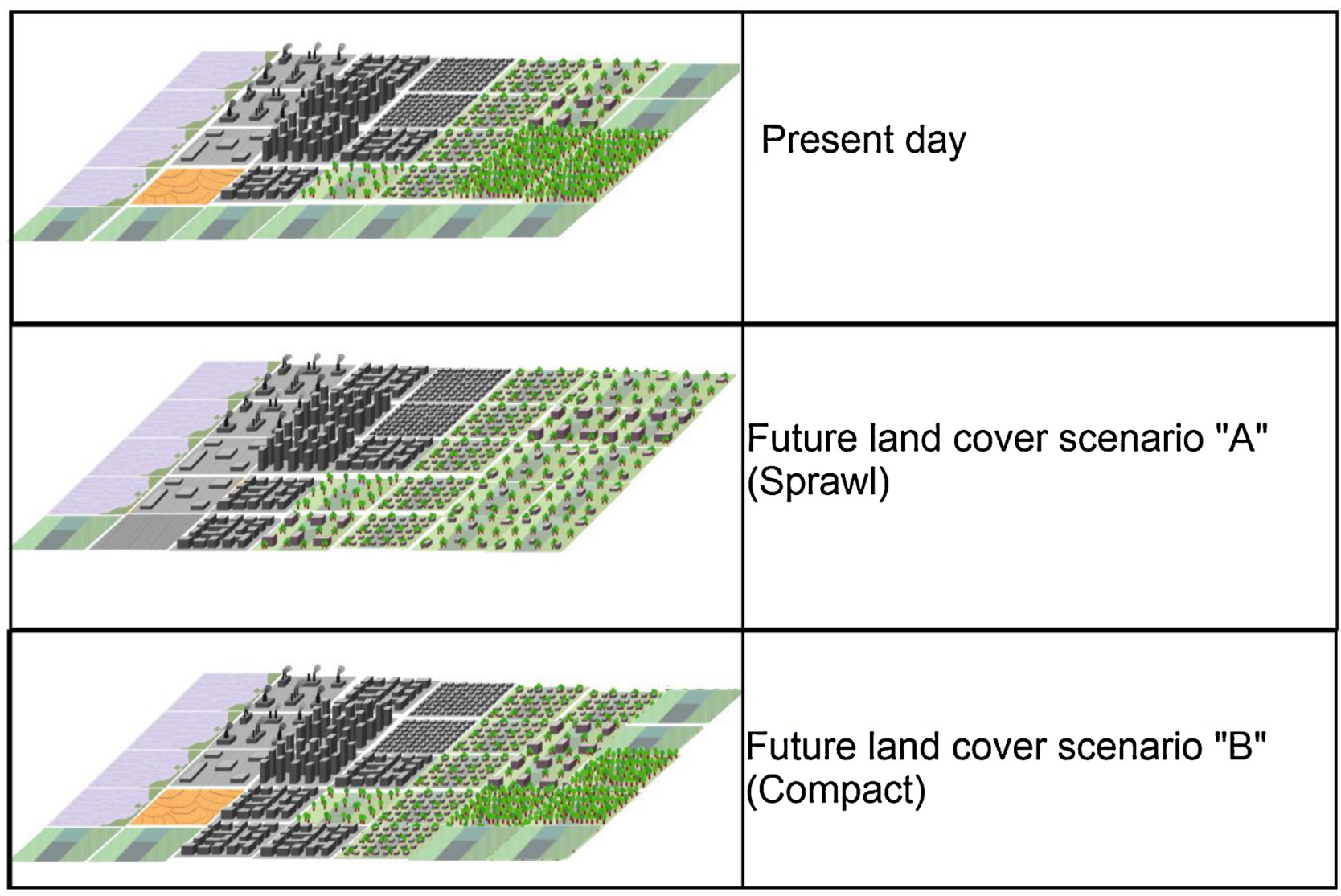

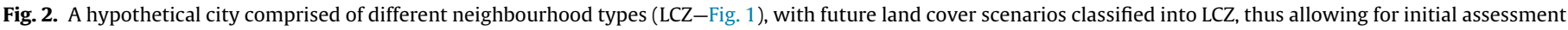
and modelling of climatic impacts of policy/planning decisions at the neighbourhood scale (see for instance Fig. 12/13 in Ching, 2013).

sparse, open or compact neighbourhood areas as well as lowrise, midrise or highrise building elements. While SUEWS cannot explicitly account for building configurations (unlike for example, the ENVI-MET model) it employs several parameters that are determined by the extent of open spaces, buildings and vegetation height and coverage. These choices of form will impact on the local scale partitioning of energy-Eq. (1) below.

SUEWS simulates the effect of urbanisation on the processes responsible for local-scale changes in the climate. These processes are encapsulated in the urban energy budget (UEB), which states

$Q *+Q_{\mathrm{F}}=Q_{\mathrm{H}}+Q_{\mathrm{E}}+\Delta Q_{\mathrm{S}}+\Delta Q_{\mathrm{A}}, \quad\left[\mathrm{W} \mathrm{m}^{-2}\right]$
$Q^{*}$ is net radiation, $Q_{F}$ is anthropogenic heat, $Q_{H}$ and $Q_{E}$ are the turbulent sensible and latent heat respectively and $\Delta Q_{S}$ is storage heat and $\Delta Q_{A}$ is advection (i.e. the horizontal transfer of energy). Each term is expressed as a flux density $\left(\mathrm{Wm}^{-2}\right)$ across the sides of an imaginary volume that encloses a section of urban landscape. The volume encloses the urban surface features (buildings, trees, etc.) and extends to a depth within the substrate where energy exchanges are close to zero; in other words, $Q^{*}, Q_{F}, Q_{H}, Q_{E}$ and $\Delta Q_{S}$ can each be assessed at the top of the volume. SUEWS does not account for advection which is significant at the boundary between surface types, and so is limited to 'homogenous' land- 
Table 2

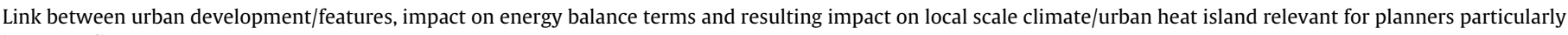
in warm climates.

\begin{tabular}{|c|c|c|}
\hline Urban feature & Urban effect & Energy balance term (Relative to non-urban areas) \\
\hline Canyon geometry & Increased surface area and trapping of radiation & Increased $\mathrm{K}^{*}$ \\
\hline Air pollution & Greater absorption and re-emission & Increased $\mathrm{L} \downarrow$ \\
\hline Canyon geometry & Reduced sky view factor (less nocturnal loss to atmosphere) & Decreased L* \\
\hline Buildings and traffic & Direct addition of heat & Addition of $Q_{F}$ \\
\hline Construction materials & Increased thermal admittance at night & Increased $\Delta Q_{S}$ \\
\hline Absence of water bodies/vegetation & Increased surface/air heating & Increased $Q_{H}$ \\
\hline Construction materials & Increased water-proofing/increase runoff & Decreased $Q_{E}$ \\
\hline Canyon geometry & Reduces wind speed & Decreased $Q_{A}$ \\
\hline
\end{tabular}

scapes (both urban and non-urban) where $\Delta Q_{A} \approx 0$. Moreover, the lack of explicit accounting for advection (strictly speaking) further limits the model to synoptic conditions conductive to a strong urban effect i.e. low winds, clear sky, high pressure. Thus, the UEB simulates the total amount of energy available at the urban surface $\left(Q^{*}+Q_{F}\right)$ and its use for heating the air $\left(Q_{H}\right)$, evaporating water $\left(Q_{E}\right)$ and heating the substrate $\left(\Delta Q_{S}\right)$. The partitioning of available energy will govern the urban impact on the substrate, surface and air temperatures and atmospheric humidity; it will also affect the UHI, building energy management and the partitioning of precipitation into runoff and storage (Table 2 ).

SUEWS is well suited to this study as it requires a relatively low number of input parameters including: meteorological data; socio-economic-demographic data and; surface cover and urban structure data, which is provided by the LCZ scheme.

We simulated neighbourhood/local scale $\left(\sim 1 \mathrm{~km}^{2}\right)$ turbulent fluxes in order to examine the impact of different development pathway scenarios on neighbourhood scale climate across a typical climatological year (TCY). We simulated hourly sensible, latent and stored heat using the Surface Urban Energy and Water balance (SUEWS v.2013b) model (Järvi et al., 2011). We forced the model with meteorological data obtained from a WMO standard station located approximately $5 \mathrm{~km}$ outside of the metropolitan area. These data are based on 10-year hourly averages, thus represent a TCY, but for clarity, the 10-year period runs from 2005-2014 which contained 3 of the warmest years on record for the region (Walsh, 2014). Hence while the TCY simulations are intended to be a-temporal, they are based on the present climate regime. The model has already been evaluated under a number of different circumstances i.e. background climates and different cities (Alexander et al., 2015; Järvi et al., 2011, 2014) and its potential utility for urban planning has been discussed elsewhere (Chrysoulakis, Anselmo, de Castro, \& Moors, 2014).

\section{Methods}

\subsection{Case study area}

Our case study area is the Greater Dublin Region (GDR) which covers Dublin city (Ireland) and parts of the surrounding counties containing several large satellite towns. Dublin is the capital city of Ireland and located on the east coast, flanked by the Irish Sea to the East, and the Dublin/Wicklow mountains to the South. With the exception of the mountainous southern part, most of the city occupies a flat and low-lowing basin ( $<100 \mathrm{~m}$ above sea level.) and is bisected by the Liffey River-Fig. 3. Despite its latitude, it has a mild climate with little temperature variation through the year (Köppen type $C f b$ ) although day-length is significantly longer in summer ( $16 \mathrm{~h}$ in June) than in winter ( $8 \mathrm{~h}$ in December). The urban area under investigation extends to $\sim 700 \mathrm{~km}^{2}$ as the city has expanded outside its administrative boundaries over the last three decades. The population of the defined model extent is $\sim 1.4$ million. Dublin provides an optimum location for undertaking this case study as it has two flux observation sites (located in urban and suburban neighbourhoods) where detailed energy flux and meteorological observations have been made since 2009 (Keogh, Mills, \& Fealy, 2012) which has allowed for model calibration and evaluation as outlined in previous studies (Alexander et al., 2015). In addition there is a LCZ description of the city that outlines major neighbourhood types (Alexander \& Mills, 2014) and a WMO standard meteorological station located outside the urban area. The LCZ map of Dublin and the meteorological data are sufficient for running SUEWS.

\subsection{Data}

SUEWS requires hourly meteorological data, land cover parameters and estimates of anthropogenic fluxes-see Table 3. In terms of land cover, the model describes different surface types in a neighbourhood in terms of fractional coverage of buildings, pavements, water, vegetated areas (both irrigated and non-irrigated) and trees (coniferous and deciduous) and unmanaged land cover such as bare soils or rock. Anthropogenic water and energy use can also be provided. In the following sections, the various input data utilised are described.

\subsubsection{Forcing data}

We obtained hourly values for temperature, relative humidity, precipitation, pressure, wind speed and incoming solar radiation for the period from 2005 to 2014 from a meteorological station located close to Dublin airport, approximately $5 \mathrm{~km}$ north of the inner city. We averaged the hourly values for each day of the year in order to derive a typical climatological year (TCY). The resulting hourly dataset was used to force the model in each of the four MOLAND scenario runs and an additional run for the base line case (BLC) to examine the impact on the urban energy budget (UEB). This allowed for an evaluation of the model simulated turbulent fluxes $\left(Q_{H} Q_{E}\right.$ and $\left.\Delta Q_{S}\right)$ against observations made at two flux sites; one urban and one suburban. Each of the flux sites carries the same suite of instruments and measures $Q^{*}, Q_{H}$ and $Q_{E}$ using an open path eddy-covariance method (see Keogh et al., 2012 for details). $\Delta Q_{S}$ is estimated as the residual of the observations (i.e. $\Delta Q_{S} \approx Q^{*}-\left[Q_{H}+Q_{E}\right]$ ) The instruments are located at approximately twice the height of their surrounding roughness elements, within relatively homogenous land cover fetches (extending outwards to approximately $\geq 1 \mathrm{~km}^{2}$ radius from the flux towers); thus are assumed to be making observations within the inertial sublayer and are representative of the neighbourhood type in which they are located. The flux data are provided as half-hourly averages for each of the flux terms, and have been shown to correspond well with SUEWS simulations forced with off-site meteorological data previously run for Dublin (Alexander et al., 2015).

\subsubsection{Land cover scenarios}

The land cover data used here are based MOLAND scenarios for Dublin up to 2026 (see Brennan et al., 2009 and Williams, 


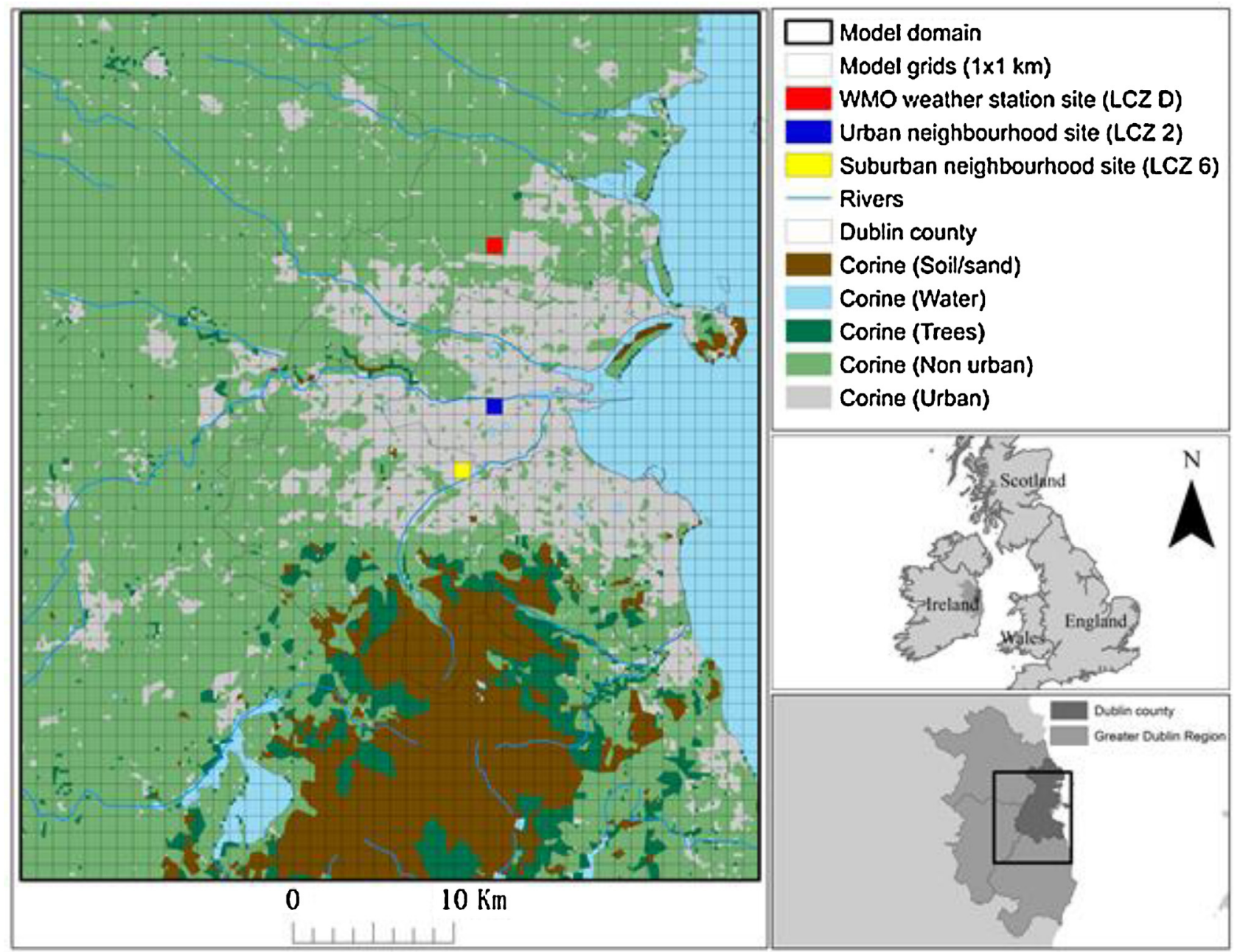

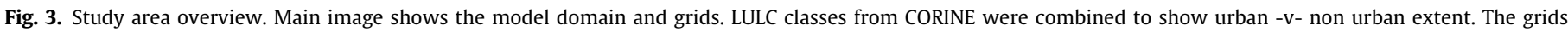

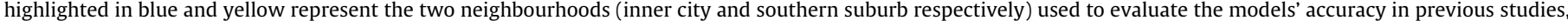

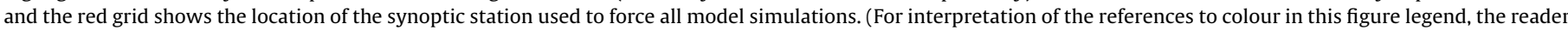
is referred to the web version of this article.)

Shahumyan, Boyle, Convery, \& White, 2012 for further details). The MOLAND cellular automata model is discussed in detail by Barredo, Kasanko, and Lavalle, 2013 however, a summary of the scenarios utilised in this study and how these were converted into land cover parameters required by SUEWS are given below.

The development scenarios used in this study are illustrated in Fig. 4. In total four scenarios were examined which are differentiated by different policy priorities and hence, development pathways pursued in order to adhere to the policy chosen. The policies informing the scenarios can be divided into two broad categories; (1) those based on current regional planning guidelines which emphasise strategic green belts between the Dublin metropolitan area and surrounding satellite towns, we refer to this development pathway as urban-densification; (2) consolidation of the metropolitan footprint (MF) with surrounding urban areas by expansion along transport corridors, we refer to this development pathway as urban-expansion (sprawl). Table 4 provides additional details on each of the four development pathway (DP) scenarios, to summarise;

(i) DP-1; business as usual development based on recent trends.

(ii) DP-2; urban-expansion along transport corridors.

(iii) DP-3; urban-consolidation with strategic satellite towns.

(iv) DP-4; urban-densification of existing MF and satellite towns.
The majority of all planned development in each DP are residential areas, which reflects the increasing demand for housing within the case study area and the density of urban coverage is determined by the population projections. Local planning regulations place restrictions on high-rise development, hence these land cover types are not included in the projections by MOLAND. In order to translate the different land cover classes utilised in the scenarios to a format usable by SUEWS (fractional coverages of buildings/pavements/vegetation/trees/water/unmanaged soils) we took the following approach:

1. The MOLAND land-use land-cover (LULC) classes were spatially correlated with a pre-existing LCZ map for Dublin. After we established a link between MOLAND and LCZ LULC we converted each MOLAND LULC between 2006 and 2026 into a corresponding LCZ code.

2. Model grids $\left(1 \mathrm{~km}^{2}\right)$ were then coded into LCZ based on a majority rule (see Fig. 5) and assigned fractional coverage based on the values given in Table 5. These values, obtained from Alexander et al. (2015), were generated by randomly sampling LCZ across Dublin and deriving a more precise fractional value for each cover type per LCZ.

3. To incorporate densification as a development policy into the model's land cover based on DP-4, the land cover fractions and 
Table 3

INPUT requirements of SUEWS model ( $\left.{ }^{*}\right)$ indicates inputs which were used in this study.

\begin{tabular}{|c|c|c|c|c|}
\hline Variable & Units & Used in this study marked with* & \multicolumn{2}{|l|}{ Comments } \\
\hline \multicolumn{5}{|l|}{ Meteorological } \\
\hline Air temperature $(T)$ & ${ }^{\circ} \mathrm{C}$ & * & & \\
\hline $\begin{array}{l}\text { Relative humidity } \\
\text { (RH) }\end{array}$ & $\%$ & * & & \\
\hline Pressure (Pr) & $\mathrm{kPa}$ & * & & \\
\hline Precipitation $(P)$ & $\mathrm{mm} \mathrm{h}^{-1}$ & * & & \\
\hline Wind speed $(V)$ & $\mathrm{m} \mathrm{s}^{-1}$ & $*$ & & \\
\hline $\begin{array}{l}\text { Incoming short } \\
\text { wave }(\mathrm{K} \downarrow)\end{array}$ & $\mathrm{W} \mathrm{m} \mathrm{m}^{-2}$ & * & & \\
\hline $\begin{array}{l}\text { Incoming long } \\
\text { wave (L } \downarrow \text { ) }\end{array}$ & $\mathrm{W} \mathrm{m}^{-2}$ & & \multicolumn{2}{|c|}{ Optional (otherwise uses T and RH) } \\
\hline $\begin{array}{l}\text { Observed sensible } \\
\text { heat }\left(Q_{H}\right)\end{array}$ & $\mathrm{W} \mathrm{m} \mathrm{m}^{-2}$ & & \multicolumn{2}{|l|}{ Optional } \\
\hline $\begin{array}{l}\text { Observed latent } \\
\text { heat }\left(Q_{E}\right)\end{array}$ & $\mathrm{W} \mathrm{m} \mathrm{m}^{-2}$ & & \multicolumn{2}{|l|}{ Optional } \\
\hline $\begin{array}{l}\text { Observed storage } \\
\text { heat }\left(\Delta Q_{S}\right)\end{array}$ & $\mathrm{W} \mathrm{m} \mathrm{m}^{-2}$ & & \multicolumn{2}{|l|}{ Optional } \\
\hline Cloud fraction & Tenths & * & \multicolumn{2}{|l|}{ Optional } \\
\hline $\begin{array}{l}\text { Soil moisture } \\
\text { deficit (SMD) }\end{array}$ & $\mathrm{m}^{3} \mathrm{~m}^{-3}$ & * & \multicolumn{2}{|l|}{ Optional } \\
\hline $\begin{array}{l}\text { Leaf area index } \\
\quad \text { (LAI) }\end{array}$ & & * & \multicolumn{2}{|l|}{ Optional } \\
\hline \multicolumn{5}{|l|}{ Anthropogenic inputs } \\
\hline $\begin{array}{l}\text { Anthropogenic } \\
\text { heat }\left(Q_{F}\right)\end{array}$ & $\mathrm{W} \mathrm{m}^{-2}$ & * & \multicolumn{2}{|c|}{ Optional, hourly values (otherwise modelled) } \\
\hline $\begin{array}{l}\text { Anthropogenic } \\
\text { water use }\end{array}$ & $\%$ & & \multicolumn{2}{|c|}{ Optional, hourly ratio of total diurnal usage } \\
\hline \multicolumn{5}{|l|}{ Surface inputs } \\
\hline $\begin{array}{l}\text { Fractional coverage } \\
\text { of surface types } \\
(\lambda)\end{array}$ & $\%$ & $*$ & & $\begin{array}{l}\text { Urban, pavement, soil, grass (irrigated and } \\
\text { un-irrigated), trees (coniferous and deciduous) } \\
\text { water }\end{array}$ \\
\hline Surface area & На & $*$ & & \\
\hline Water usage area & $\mathrm{Ha}$ & & \multicolumn{2}{|l|}{ Optional } \\
\hline Latitude/longitude & $\circ$ & $*$ & & \\
\hline $\begin{array}{l}\text { Storage capacity of } \\
\text { pipes }\end{array}$ & $\mathrm{mm}$ & & \multicolumn{2}{|l|}{ Optional } \\
\hline $\begin{array}{l}\text { Frontal area } \\
\text { fractions }\end{array}$ & & & \multicolumn{2}{|c|}{ Optional, buildings and trees separate } \\
\hline $\begin{array}{l}\text { Roughness length } \\
\text { for momentum } \\
\left(z_{0}\right)\end{array}$ & $\mathrm{m}$ & & \multicolumn{2}{|l|}{ Optional } \\
\hline $\begin{array}{l}\text { Zero displacement } \\
\text { height }\left(z_{\mathrm{d}}\right)\end{array}$ & $\mathrm{m}$ & & \multicolumn{2}{|l|}{ Optional } \\
\hline $\begin{array}{l}\text { Surface element } \\
\text { heights }\end{array}$ & $\mathrm{m}$ & * & & Optional, buildings and trees separate \\
\hline
\end{tabular}

building heights for several urban LCZ were modified for the DP4 model run.

While high-rise development (and very sparse urban development) are excluded from this case study, in other domains where local regulations do not prohibit this type of urban land cover a wider range of LCZ could be tested using this approach.

\subsubsection{Anthropogenic Data}

SUEWS is capable of simulating the addition of local scale anthropogenic heat $\left(Q_{\mathrm{F}}\right)$ utilising specified population density per grid and a daily mean $Q_{F}$ value, which is adjusted based on a diurnal energy use profile. The population density per grid was obtained from the national census of Ireland (C.S.O., 2012). Population density extrapolated for 2026 was based on the population growth trends from previous census statistics-see Table 5. For the model simulations, weekday and weekends are differentiated with two separate hourly $\mathrm{Q}_{F}$ profiles. The weekday profile assumes an increase in $Q_{F}$ from 05:00 h (local time) through to 09:00 h associated with typical commuting patterns and business activity hours. A second peak occurs between 17:00 $\mathrm{h}$ and 18:00 $\mathrm{h}$ associated with traffic flows leaving the city, with a gradual-steady decline thereafter. The weekend profile is similar, but has no peak around the so-called rush hours, rather a steady increase and consistent $Q_{F}$ throughout the day, $Q_{F}$ declines at 22:00 h rather than 17:00 h which is the case for the weekday profile. An estimate of annual $Q_{F}$ was obtained from a lookup Table (Flanner, 2009) and was then weighted for each month. $Q_{F}$ was set to be slightly lower in summer months (May-September) than the winter months to reflect reduced space heating demand in summer/increased heating in winter and increased car usage etc. as would be expected for a middle-latitude city (Offerle, Grimmond, \& Fortuniak, 2005).

\section{Results}

In the following sections, an analysis of the SUEWS simulations of local scale turbulent fluxes across each neighbourhood is given, focusing on how form (openset verses compact) and function impacts the local climate. Firstly, the impact of the four MOLAND development pathways (DPs) relative to the base line case (BLC) is analysed with respect to the annual and seasonal partitioning of available energy into sensible, latent and stored heat and the spatial distribution across the study area in each DP. To highlight the impact of each DP, we derived the sensible heat index $\left(\chi: Q_{H} / Q^{*}\right)$, the evaporation index $\left(\gamma: Q_{E} / Q^{*}\right)$, the storage index $\left(\Lambda: \Delta Q_{S} / Q^{*}\right)$ and the Bowen ratio $\left(\beta: Q_{H} / Q_{E}\right)$ since these have direct impact on 

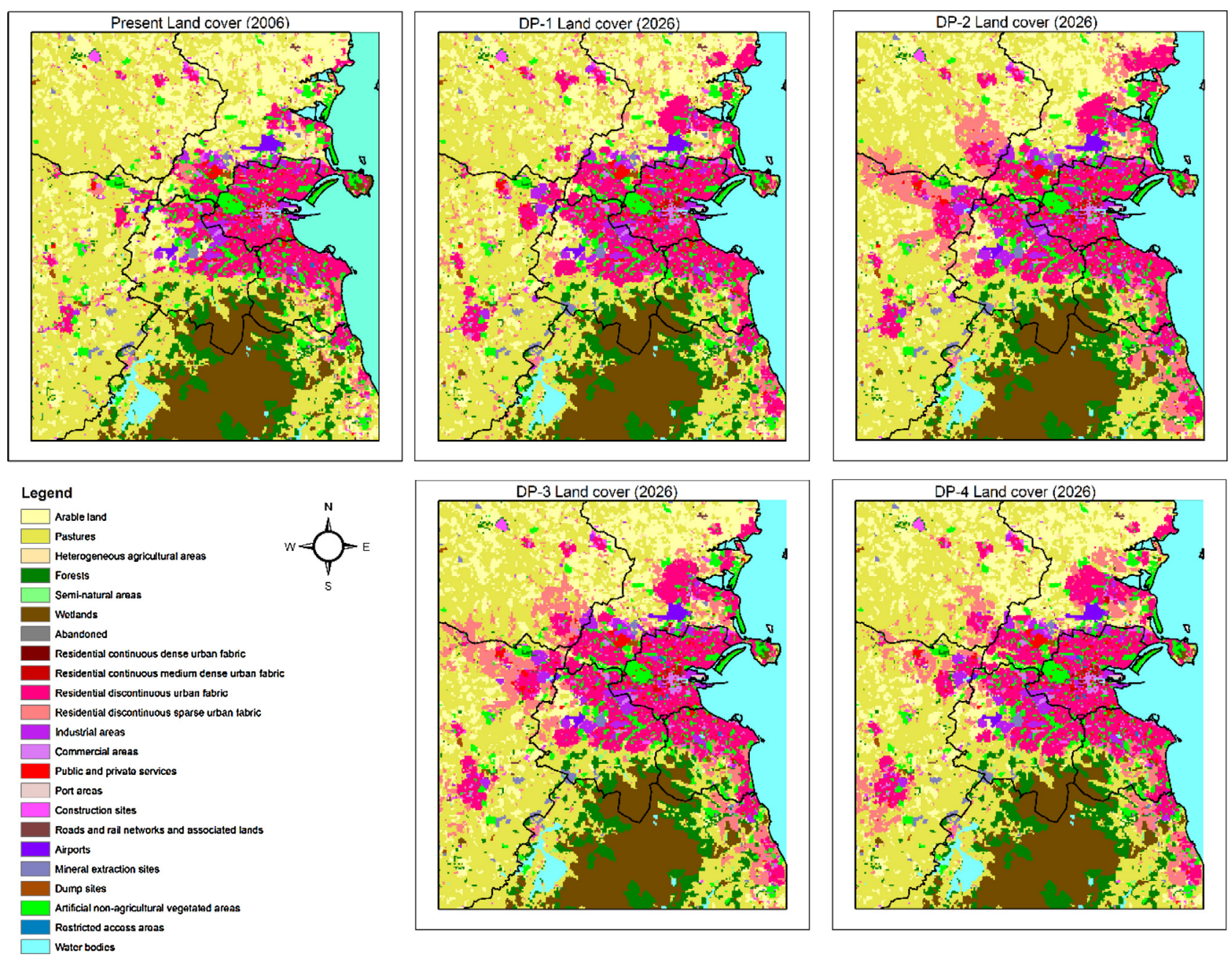

Fig. 4. Overview of present day CORINE land cover classes for study area (top left panel) with development pathway scenarios 1-4-see text/ Table 4 for more details.

Table 4

Outline of the development pathway (DP) scenarios utilised in this study. Further details are provided in Brennan et al. (2009). Urban extent is defined as \% of modelled grids that are classed as urban Local Climate Zones (LCZ) the \% in parenthesis is the increase in urban LCZ from the 2006 base line case-see Table 4 and Fig. 3.

\begin{tabular}{lll}
\hline Scenario short name & Alias & Description \\
\hline DP-1 & Business as usual & $\begin{array}{l}\text { As the alias suggests, this scenario explores a continuation of the } \\
\text { current, dispersed settlement patterns. Therefore,this pathway }\end{array}$
\end{tabular}

current, dispersed settlement patterns. Therefore this pathway simulates a "business as usual" future, whereby implementation of pre-existing development policies has been weak. Reflecting the current economic climate, several transportation projects are delayed in this scenario until 2020. With the divergence of policy and practice concerning Green Belts in mind, this scenario does not contain a greenbelt layer as outlined in Brennan et al. (2009) In this scenario development is strongly directed toward an expanded metropolitan footprint (MF), which is extended along key transport corridors. Strictly enforced Strategic Green Belts are used to discourage excessive development in rural areas and link protected areas together. Two types of Green Belts were created; large Outer Green Belts designed to designate areas where development should be kept to a minimum; and smaller Connector Green Belts, designed to preserve links between urban green space and rural areas was focused within the existing envelope of the MF and towards a limited number of key towns in the Hinterland. Increased densities were delivered by infilling areas within the MF and in the main towns of the Hinterland. Green Belts were more extensive and strategically placed than DP-2

In this scenario, consolidation is promoted; development is focused within the existing MF and development centres. Growth in the Mid-East at public transport nodes within the MF and in designated towns on high quality public transport routes. Although densification within the existing MF was a focus of this scenario, there was a drive to keep towns distinct from one another 
Table 5

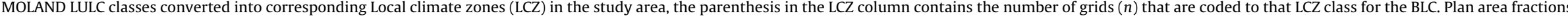

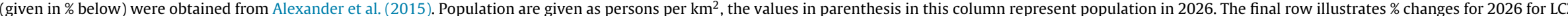
2 DP-4 only.

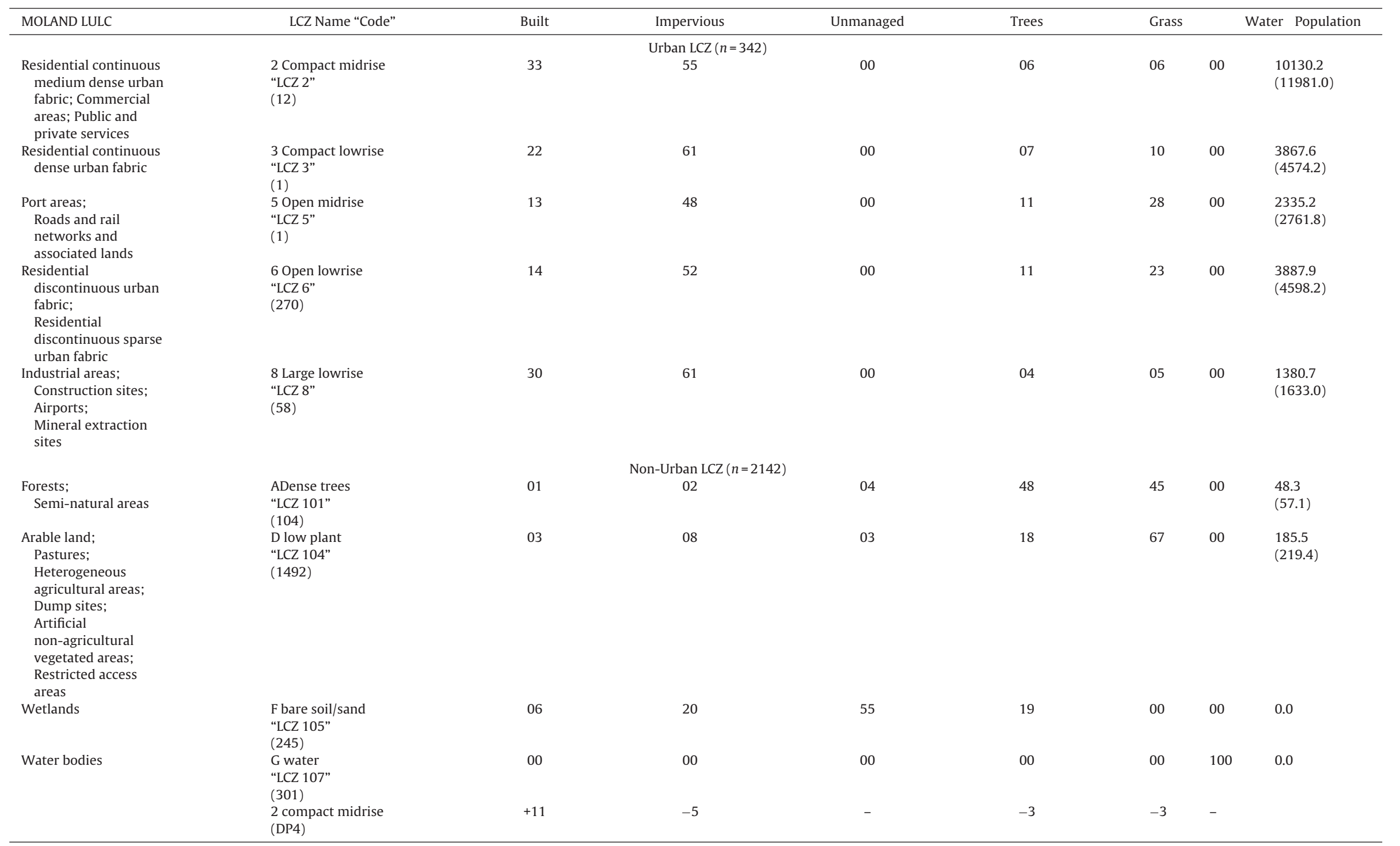



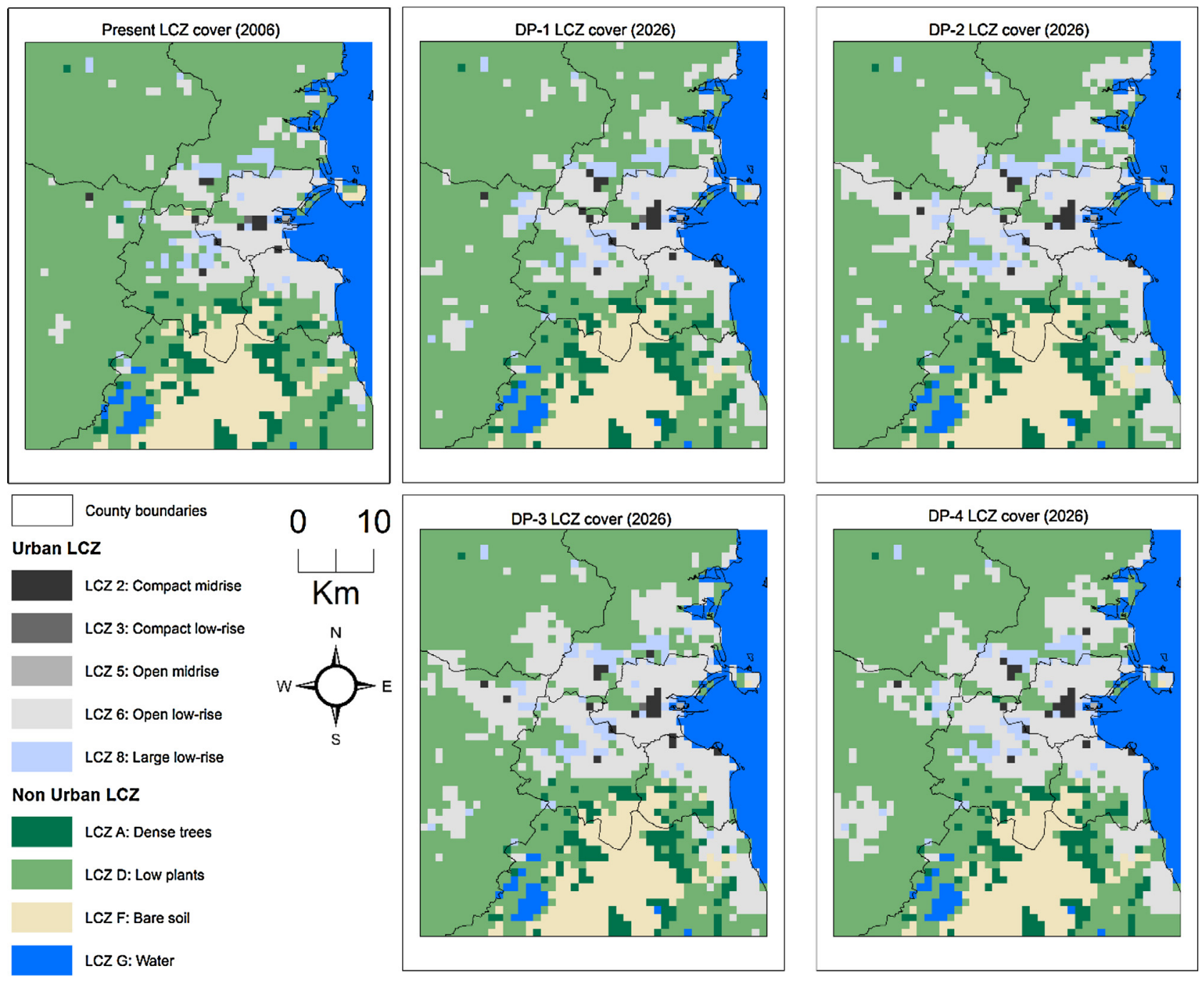

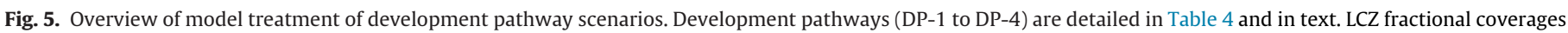
are given in Table 5. Each grid is coded into LCZ based on majority rule.

the local climate (Table 2). The diurnal profiles of each local climate zone (LCZ) class are then discussed in relation to areas which undergo urban development in each of the four DPs. An assessment of urban design interventions designed to reduce the amount of energy challenged into sensible and stored heat are then presented.

\subsection{Annual and seasonal flux variation}

The annual magnitude of sensible heating for LCZ 2 was $60.52 \%$ compared to $55.82 \% .0$ and $53.98 \%$ for LCZ 6 and LCZ D respectively in the BLC. The impact of DP1-3 was to increase sensible heating by $2.7 \%$ and by $7.0 \%$ in DP4 for LCZ 2 areas. The increase in LCZ 6 and LCZ D was the same for all DPs, $1.2 \%$ and $0.1 \%$ respectively. Mean heat storage for non-urban LCZ in the BLC was 16.04-19.03\% excluding water bodies which as expected were a significant store of energy (for water bodies, LCZ F, 26.54\% of incoming energy was stored on average). LCZ 2 had an annual value of $53.02 \%$ which was higher than the most abundant non-urban LCZ class (LCZ D) value which only stored $19.03 \%$ of available energy. For LCZ 6, which is spatially related to residential areas, heat storage was $31.95 \%$. This ranking (highest to lowest energy store) was maintained across all DPs, though there was a slight difference. In DP1-3 LCZ heat storage increased by 3\% for LCZ 2 (inner city areas) and by $1 \%$ for LCZ 6 (residential suburban areas) whereas for DP4, storage was decreased by $\sim 2 \%$ from the BLC, the increase for LCZ 6 was the same as DP1-3. This LCZ relationship relates to the urban heat island, leading to warmer air temperatures in compact areas of the city compared to vegetated areas and has been demonstrated previously (Alexander \& Mills, 2014; Graham, 1993; Sweeney, 1987). The differences in the annual mean values in terms of the amount of energy for surface/air heating and evapotranspiration in each LCZ type are illustrated in Fig. 6a. In all DP scenarios, the presence of water and vegetated LCZ reduced the annual magnitude of sensible heating and heat storage and increased the annual magnitude of evapotranspiration thus decreasing daytime and nighttime temperatures and reducing surface runoff as more energy was used for evaporation.

The seasonal differences between LCZ in each DP was similar to the annual partitioning of energy, although there was a greater distinction during the summer and winter period in terms of differences in mean $Q_{H}$ and $Q_{E}$ respectively-Fig. 6b. During the summer period, mean $Q_{H}$ was $82.7,70.2$ and $66.9 \mathrm{~W} \mathrm{~m}^{-2}$ for LCZ 2, 6 and $D$ respectively. In winter, mean $Q_{H}$ was $34.4,22.3$ and $11.2 \mathrm{~W} \mathrm{~m}^{-2}$ for the same three classes. Hence, there was a larger difference in sensible heat in winter between LCZ 2 and D than in summer. The opposite relationship existed between these LCZ for evapotranspiration, where the difference in summer was greater compared to winter as expected. 


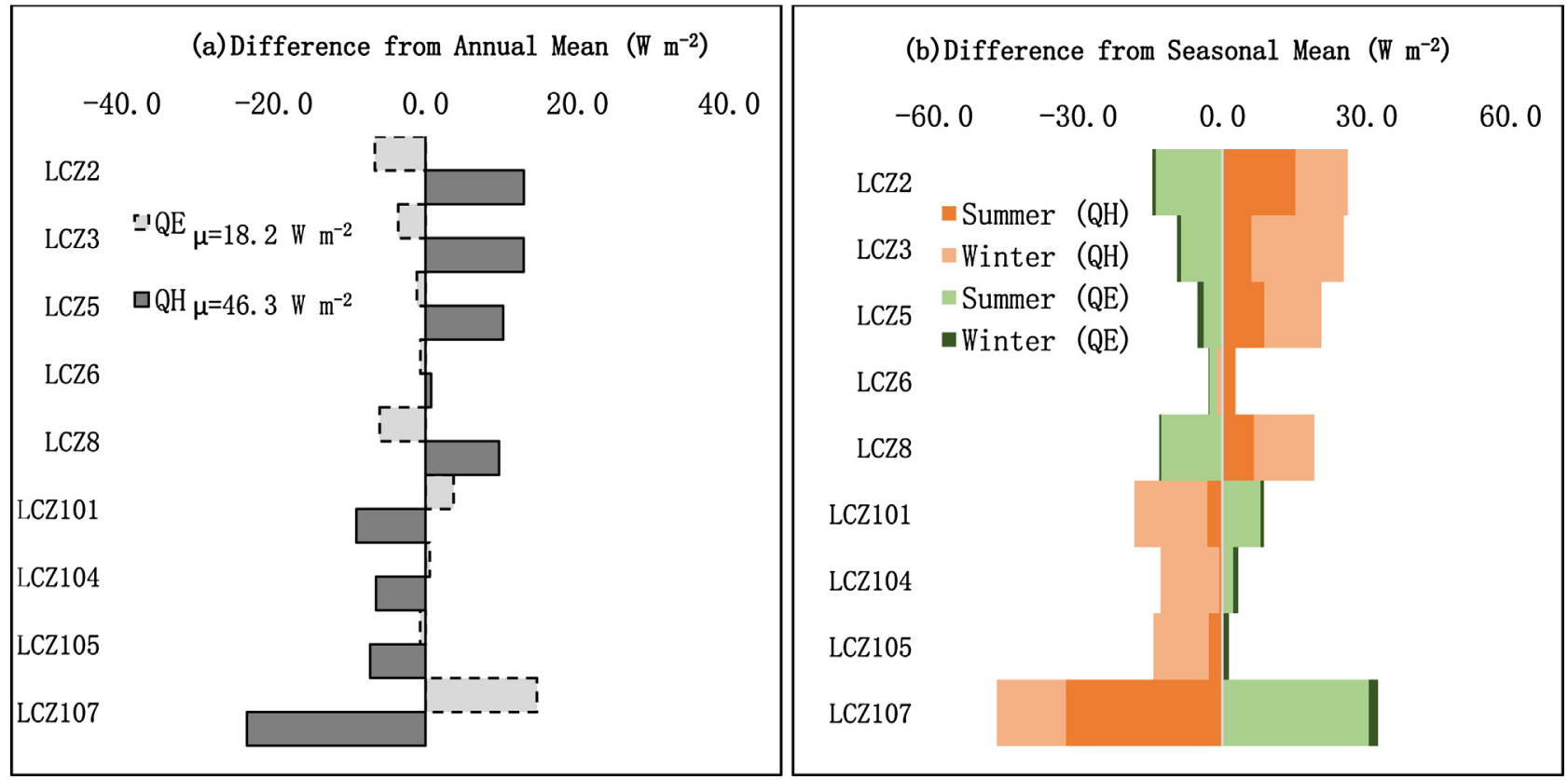

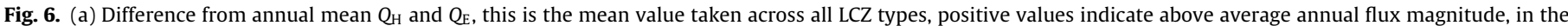

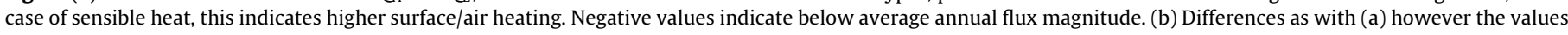

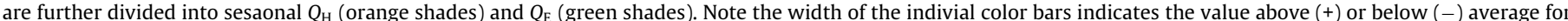

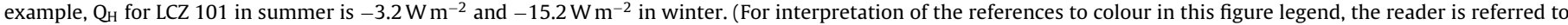
the web version of this article.)

Table 6

Proportioning of $Q^{*}(\chi, \gamma, \Lambda)$ and the Bowen ratio $(\beta)$ when $Q^{*} \geq 0 \mathrm{~W} \mathrm{~m}^{-2}$. Presented are unit-less flux ratios for annual and seasonal partitioning.

\begin{tabular}{|c|c|c|c|c|c|c|c|c|c|c|c|c|}
\hline \multirow[b]{2}{*}{ LCZ Code } & \multicolumn{3}{|c|}{$X\left(Q_{H} / Q^{*}\right)$} & \multicolumn{3}{|c|}{$\gamma\left(Q_{E} / Q^{*}\right)$} & \multicolumn{3}{|c|}{$\Lambda\left(\Delta Q_{s} / Q^{*}\right)$} & \multicolumn{3}{|c|}{$\beta\left(Q_{H} / Q_{E}\right)$} \\
\hline & Ann & Sum & Win & Ann & Sum & Win & Ann & Sum & Win & Ann & Sum & Win \\
\hline LCZ2 & 0.675 & 0.572 & 1.024 & 0.115 & 0.103 & 0.178 & 0.507 & 0.465 & 0.634 & 5.884 & 5.541 & 5.764 \\
\hline LCZ3 & 0.568 & 0.449 & 0.953 & 0.139 & 0.133 & 0.195 & 0.323 & 0.397 & 0.042 & 4.098 & 3.368 & 4.882 \\
\hline LCZ5 & 0.591 & 0.499 & 0.896 & 0.168 & 0.166 & 0.215 & 0.265 & 0.346 & -0.038 & 3.522 & 3.001 & 4.160 \\
\hline LCZ6 & 0.573 & 0.507 & 0.771 & 0.192 & 0.196 & 0.227 & 0.330 & 0.357 & 0.226 & 2.976 & 2.586 & 3.401 \\
\hline LCZ8 & 0.563 & 0.468 & 0.873 & 0.115 & 0.107 & 0.171 & 0.236 & 0.332 & -0.115 & 4.901 & 4.387 & 5.102 \\
\hline LCZ101 & 0.515 & 0.504 & 0.512 & 0.268 & 0.282 & 0.255 & 0.158 & 0.211 & -0.033 & 1.921 & 1.787 & 2.005 \\
\hline LCZ104 & 0.544 & 0.519 & 0.593 & 0.228 & 0.239 & 0.236 & 0.187 & 0.237 & 0.014 & 2.383 & 2.176 & 2.515 \\
\hline LCZ105 & 0.516 & 0.489 & 0.573 & 0.205 & 0.216 & 0.213 & 0.223 & 0.277 & 0.036 & 2.513 & 2.262 & 2.688 \\
\hline LCZ107 & 0.241 & 0.214 & 0.308 & 0.339 & 0.396 & 0.249 & 0.264 & 0.338 & 0.002 & 0.713 & 0.541 & 1.239 \\
\hline
\end{tabular}

The annual and seasonal differences in energy partitioning between LCZ are summarised in Table 6. Generally the ratio of turbulent fluxes to available energy is consistent with previous work (Grimmond \& Oke, 1995; Keogh et al., 2012; Ward, Evans, \& Grimmond, 2014). For urban LCZ, the available energy was predominantly channelled into surface/air heating and heat storage (annual sensible heat ranged from 56 to 68\%; evapotranspiration ranged from 10 to $19 \%$ and heat storage ranged from 24 to 50\%) whereas for the non-urban LCZ a higher fraction of the available energy was partitioned into evapotranspiration (annual sensible heat ranged from 24 to 50\%; evapotranspiration ranged from 20 to $34 \%$ and heat storage ranged from 16 to $26 \%$ ). There was also a seasonal pattern to the Bowen ratio (the relationship between $Q_{H}$ and $Q_{E}$ ) found in all LCZ. All areas showed lower $\beta$ values in summer relative to winter, meaning a slightly higher proportion of turbulent exchange was channelled into evapotranspiration during summer months.

\subsection{Spatial differences between different development pathways}

To examine the spatial variation between DPs impact on the BLC, the annual average of each of the indices were calculated in each grid cell (Fig. 7) based on hourly values across the entire TCY. To assess the impact relative to the BLC, differences on a grid-by-grid basis were calculated by subtracting the annual mean of the BLC from each of the DPs. To examine significant spatial clustering of differences from the BLC, Getis-Ord $G_{i}^{*}$ (Getis \& Ord, 1992; Ord \& Getis, 1995) was employed which compares local averages to the global averages. In this case, $G_{i}^{*}$ illustrates where there are spatial clustering of increases and decreases in the turbulent fluxes relative to the BLC-see Fig. 7. This reveals the geographical impact of each DP and identifies specific areas ideal for planning interventions. The partitioning of the annual fluxes for the LCZ classes follows what would be expected in each of the DP scenarios, grids which contain highly urbanised land cover (for instance the compact LCZ 2 and 3) exhibited the highest annual value of sensible heating and heat storage and the lowest annual magnitude of evapotranspiration concentrated around the inner city, whereas grids containing a higher vegetative fraction exhibited comparatively lower values of sensible heating and heat storage and higher evapotranspiration.

As expected, the sprawling scenarios (DP2 and DP3) exhibited the largest spatial increase (that is, the number of areas with higher annual values compared to the BLC) in sensible heating and heat storage coupled with the largest decrease in evapotranspi- 

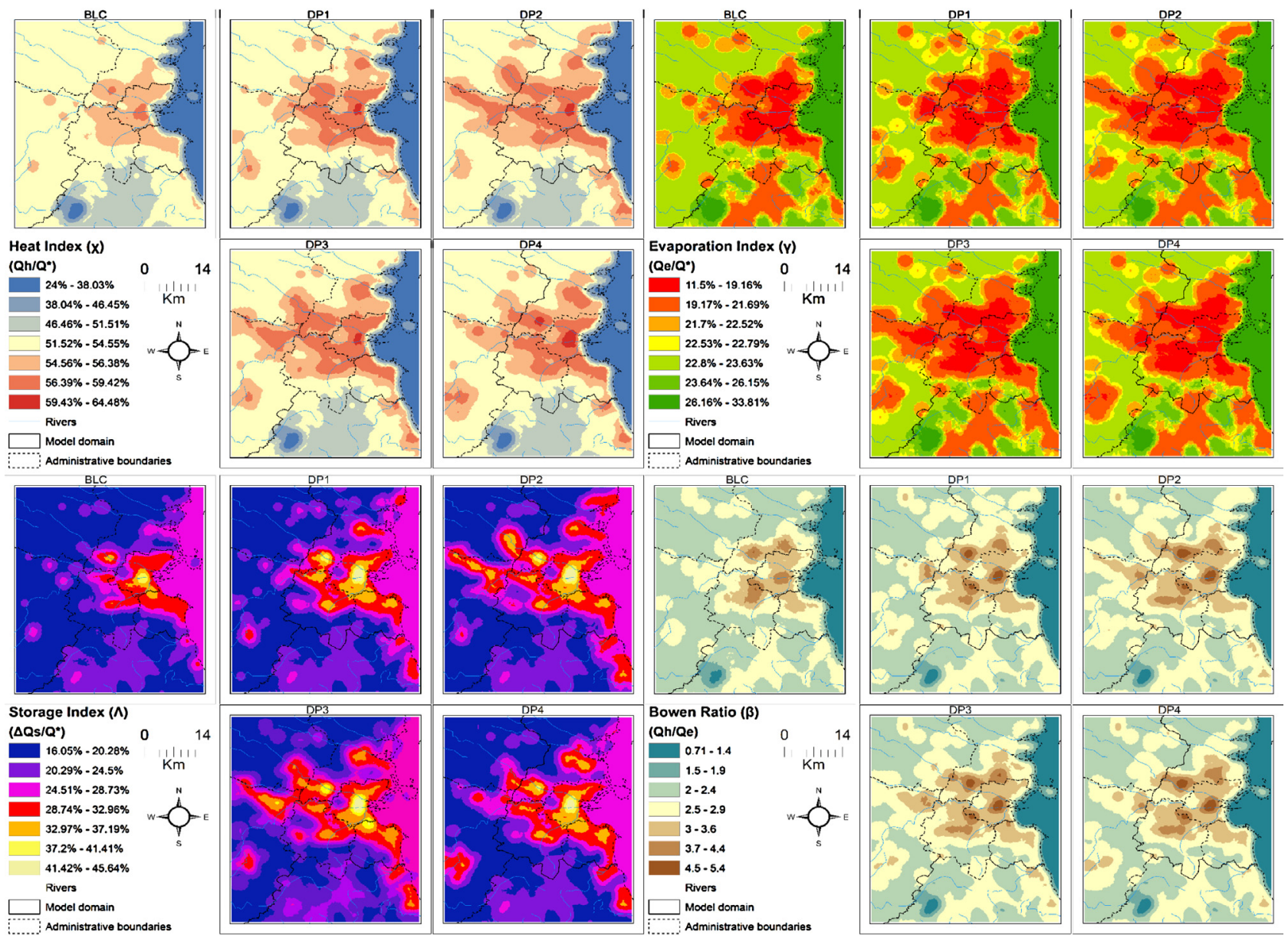

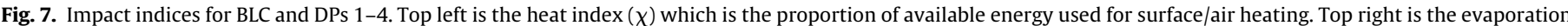

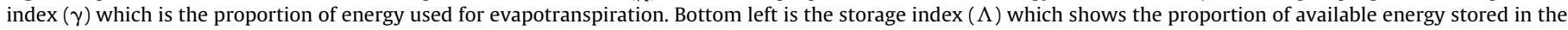

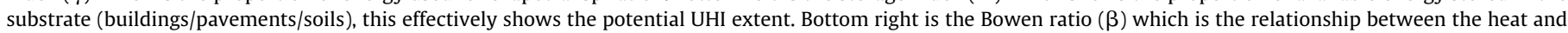
evaporative index, a higher number indicates more energy is used for surface/air heating meaning less water is evaporated hence is available for runoff.

Table 7

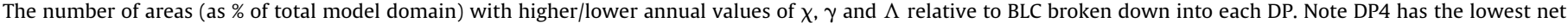
spatial impact meaning increases in one part of the city are offset by decreases in other parts.

\begin{tabular}{|c|c|c|c|c|c|c|c|}
\hline \multirow[t]{2}{*}{ Development pathway } & \multirow{2}{*}{$\begin{array}{l}\text { Net spatial increase/decrease compared to BLC } \\
\left(\Sigma_{\text {Increase }}-\text { Decrease }\right)\end{array}$} & \multicolumn{6}{|c|}{ Significance level } \\
\hline & & $+99 \%$ & $+95 \%$ & $+90 \%$ & $-90 \%$ & $-95 \%$ & $-99 \%$ \\
\hline \multicolumn{8}{|l|}{ DP1 } \\
\hline Heat index $\chi\left(Q_{H} / Q^{*}\right)$ & $8.9 \%$ & $4.8 \%$ & $4.9 \%$ & $0.2 \%$ & $0.0 \%$ & $0.0 \%$ & $1.0 \%$ \\
\hline Evaporation index $\gamma\left(Q_{E} / Q^{*}\right)$ & $-2.2 \%$ & $1.3 \%$ & $0.3 \%$ & $0.7 \%$ & $0.9 \%$ & $1.7 \%$ & $1.9 \%$ \\
\hline Storage index $\Lambda\left(\Delta Q_{S} / Q^{*}\right)$ & $7.7 \%$ & $7.9 \%$ & $0.4 \%$ & $0.7 \%$ & $0.8 \%$ & $0.1 \%$ & $0.4 \%$ \\
\hline \multicolumn{8}{|l|}{ DP2 } \\
\hline Heat index $\chi\left(Q_{H} / Q^{*}\right)$ & $12.1 \%$ & $7.8 \%$ & $3.4 \%$ & $2.1 \%$ & $0.0 \%$ & $0.1 \%$ & $1.1 \%$ \\
\hline Evaporation index $\gamma\left(Q_{E} / Q^{*}\right)$ & $-4.4 \%$ & $1.5 \%$ & $0.3 \%$ & $0.7 \%$ & $2.0 \%$ & $2.4 \%$ & $2.5 \%$ \\
\hline Storage index $\Lambda\left(\Delta Q_{S} / Q^{*}\right)$ & $14.9 \%$ & $9.2 \%$ & $2.1 \%$ & $4.3 \%$ & $0.1 \%$ & $0.5 \%$ & $0.1 \%$ \\
\hline \multicolumn{8}{|l|}{ DP3 } \\
\hline Heat index $\chi\left(Q_{H} / Q^{*}\right)$ & $12.9 \%$ & $8.5 \%$ & $2.7 \%$ & $2.9 \%$ & $0.0 \%$ & $0.0 \%$ & $1.2 \%$ \\
\hline Evaporation index $\gamma\left(Q_{E} / Q^{*}\right)$ & $-4.0 \%$ & $1.4 \%$ & $0.3 \%$ & $0.6 \%$ & $0.8 \%$ & $2.5 \%$ & $3.0 \%$ \\
\hline Storage index $\Lambda\left(\Delta Q_{S} / Q^{*}\right)$ & $14.9 \%$ & $9.0 \%$ & $2.8 \%$ & $3.7 \%$ & $0.5 \%$ & $0.1 \%$ & $0.0 \%$ \\
\hline \multicolumn{8}{|l|}{ DP4 } \\
\hline Heat index $\chi\left(Q_{H} / Q^{*}\right)$ & $0.1 \%$ & $6.1 \%$ & $0.1 \%$ & $0.2 \%$ & $3.1 \%$ & $0.5 \%$ & $2.7 \%$ \\
\hline Evaporation index $\gamma\left(Q_{E} / Q^{*}\right)$ & $0.0 \%$ & $1.9 \%$ & $0.3 \%$ & $1.2 \%$ & $0.2 \%$ & $1.1 \%$ & $2.1 \%$ \\
\hline Storage index $\Lambda\left(\Delta Q_{s} / Q^{*}\right)$ & $0.7 \%$ & $5.6 \%$ & $0.4 \%$ & $0.4 \%$ & $2.9 \%$ & $0.2 \%$ & $2.6 \%$ \\
\hline
\end{tabular}

ration (see Table 7). Taking the number of areas with increased sensible heating relative to the BLC; DP3 exhibited the largest spatial increase (increasing in $14.1 \%$ of the modelled area) followed by DP2 (13.3\% increase in area), DP1 (9.9\% increase in area) and finally DP4 (6.4\% increase in area). When the number of grids with decreases relative to the BLC were also taken into account, the ranking remained the same. The ranking for the number of areas with decreases in evapotranspiration were similar, however the number of areas in DP2 relative to the BLC was marginally higher than DP3 (6.9\% and 6.3\% respectively). Decreases in evapotranspiration were 


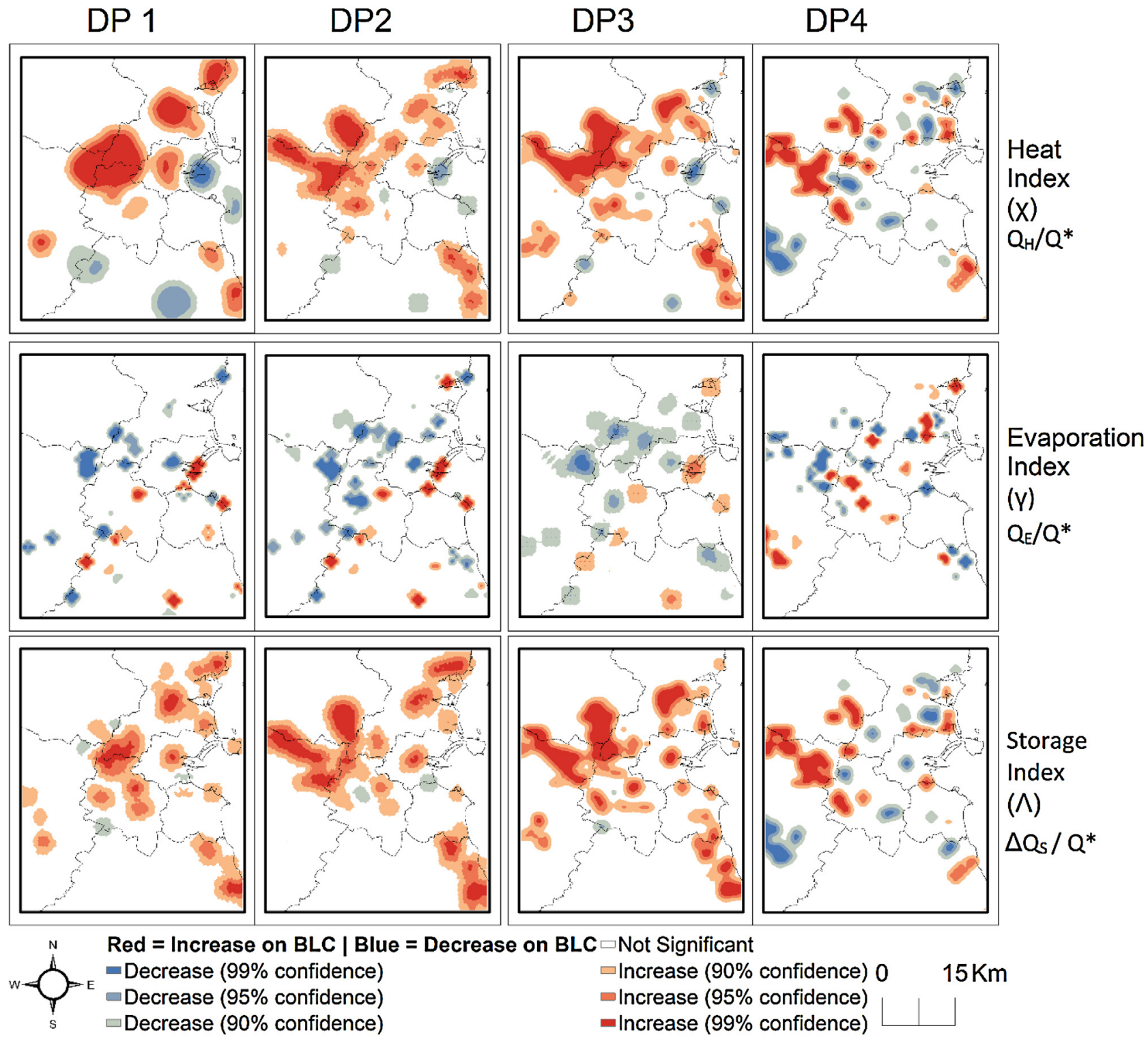

Fig. 8. Spatial distribution of increases/decreases in impact indices compared to BLC for each DP (columns). The differences are based on annual mean values.

greater in DP1 than DP4. For storage, which illustrates the potential of the UHI, the ranking was DP2 (15.6\%) followed closely by DP3 (15.5\%) then DP1 (9\%) and DP4 (6.4\%). Out of the four scenarios DP4 had the least impact in respect to the number of areas with surface/air temperature increases, evapotranspiration decreases and heat storage increases (Fig. 8).

To further investigate the spatial differences between DP scenarios, 3 subsets of the model domain were examined based on these impact hotspots (see Fig. 9) located around the inner city and 2 non-urban areas which became urbanised in each DP scenario. These were also used for examination of the diurnal energy profiles (Section 4.3). Within these subset areas, the type of development in each DP controlled the impact relative to the BLC. The replacement of LCZ D with LCZ 6 in the case of DP1-3 had the largest impact relative to BLC sensible heating. There were marginal increases in sensible heating and heat storage in the inner city where LCZ 3 was replaced with LCZ 2 in DP1-4. The impact on evapotranspiration was lower in LCZ 6 areas owning to their higher level of vegetation compared to LCZ 2/3. In the suburban subsets, DP4 was again identified as having the least impact compared to DP1, 2 and 3.
In a study by Demuzere, Oleson, Coutts, Pigeon, and van Lipzig (2013) which simulated the impact of different urban environments on the surface energy balance, a similar energetic-hierarchy was found between compact and openset residential thermal climate zones, which are an earlier iteration of the LCZ 2 and LCZ 6 classes respectively. The reduction in vegetation fraction leads to a minor decrease in evapotranspiration though the larger impact is found in terms of heat storage as the heat capacity of these areas significantly increases due to the additional buildings and pavements. Work by Stewart et al. (2014) which examines the impact of this hierarchy on air temperatures differences across LCZ, highlights the impact of this on the UHI and diurnal temperature range across different LCZ.

\subsection{Impact of development on seasonal diurnal fluxes}

Fig. 10 illustrates the findings related to seasonal differences in energy budgets within the subset areas due to land cover change. For the inner-city subset, compact lowrise areas (LCZ3-Fig. 10c) in the BLC were replaced with compact midrise areas (LCZ2-Fig. 10a) 


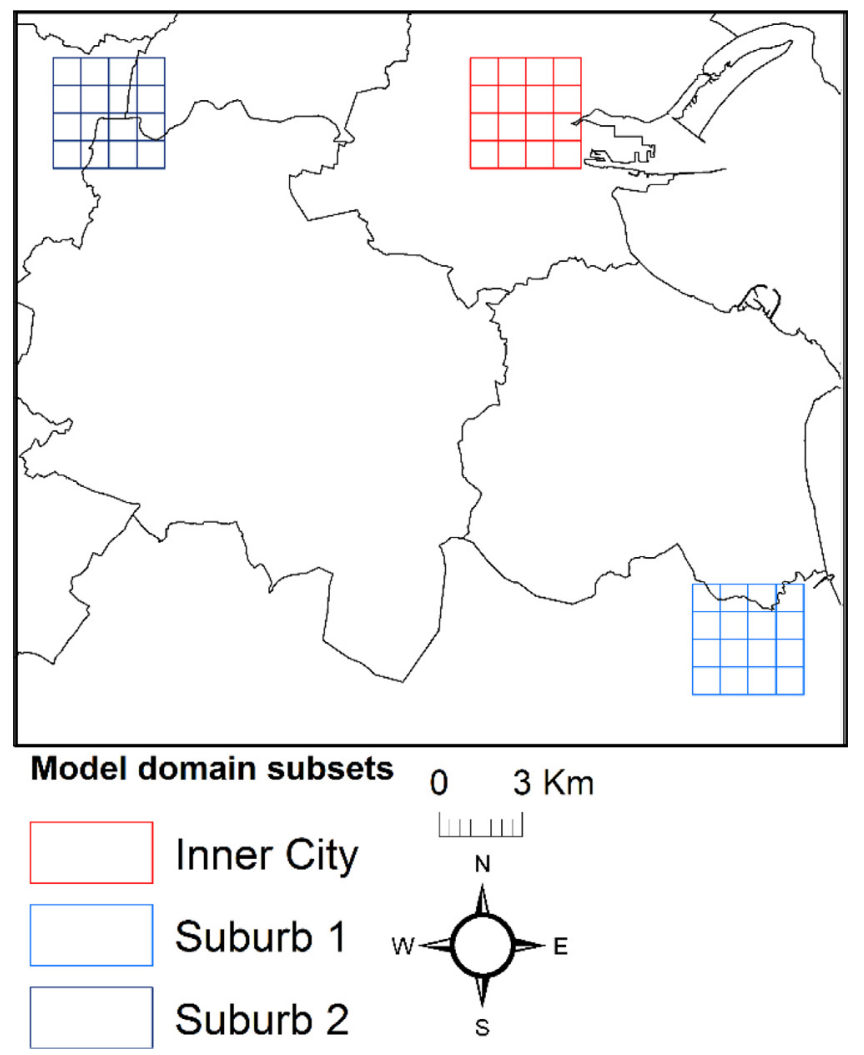

Fig. 9. Illustration of the domain subsets for detailed analysis of change in each DP and diurnal analysis (Section 4.2).

in each of the four DP scenarios. The most distinguishable effect of this was to increase heat storage during both winter and summer and introduce significant hysteresis into the energy budget around these areas. Note for instance, LCZ 3 (BLC) the close temporal correspondence between available energy and heat storage in terms of the diurnal profile, whereas for LCZ 2 (DPs) a lag of $6 \mathrm{~h}$ between the time available energy and heat storage both reach a minima value. We hypothesise that due to decreased Sky View Factor $(\Psi)$, increased height to width ratio $(\mathrm{H} / \mathrm{W})$ and decreased effective albedo, which are parameterised in the LCZ concept, heat withdrawal became less efficient across the inner-city urban subset in each DP scenario relative to the BLC. This applied for both winter and summer.

For the suburban subsets, vegetated areas with low plant cover (LCZ D-Fig. 10d) were replaced with residential areas (LCZ 6-Fig. 10b) in each of the DP scenarios, though the number of areas in the subset varied between DP1-4. In cases where LCZ D was replaced with LCZ 6, the impact during winter was an increase in surface/air heating during all hours, though the increase was slightly higher during daylight hours. Heat storage was increased by during daylight hours. There was little distinction in evapotranspiration though it was marginally higher for LCZ 6.

During the summer, daytime surface/air heating in the urban subset increased significantly at midday. Evaporation during the day was reduced. In the suburban subsets, the largest impacts were on heat storage, which increased significantly at midday, and a reduction in evapotranspiration for all daylight? hours similar to winter, though there was a tenfold increase in the difference during summer.

\subsection{Design interventions for low impact development}

Based on the previous sections, DP4 had the least impact on the annual, seasonal and spatial fluxes across the model domain across all scenarios considered. Therefore, we define this as the optimum growth pathway in terms of reducing the spatial impact on the local climate. To examine how sustainable design might be coupled with this type of growth to further reduce the impact on the UEB, several design interventions were tested using DP4 as the growth scenario-see Table 8. The first design intervention was simply to rebalance the ratio of vegetated to paved areas and modify the type of tree species. The second design intervention was to reduce the overall building footprint by instead promoting upward development. Therefore, building heights were modified and expansive green spaces encouraged, as with the first intervention, tree species were modified however an equal mix of deciduous and coniferous trees were used. The third intervention was an extension of this, however additionally roof tops for all buildings were greened. The aim was to reduce the seasonality in evapotranspiration i.e. increase energy partitioning into evapotranspiration during winter and decrease annual fluxes of surface/air heating and heat storage relative to LCZ D areas in the BLC.

The first design intervention is the most modest, in that it simply controls the type and level of vegetation in future developments, specifically, the replacement of LCZ D with LCZ 6. The result was to reduce the impact of urban development on summertime evapotranspiration by $34.0 \%$. Both the second and third design interventions which further modified the coverage and type of buildings reduced the impact further. The second design reduced the impact on summertime evapotranspiration by $47.7 \%$, the third design reduced the impact by $52.2 \%$.

The impact of urban development on the annual magnitude of surface/air heating was reduced by $30.1 \%, 37.5 \%$ and $38.6 \%$ in design 1,2 and 3 respectively, the impact on heat storage was reduced by $7.9 \%, 15.8 \%$ and $21.7 \%$, meaning the green roof design reduced the impact of urban development the most. 


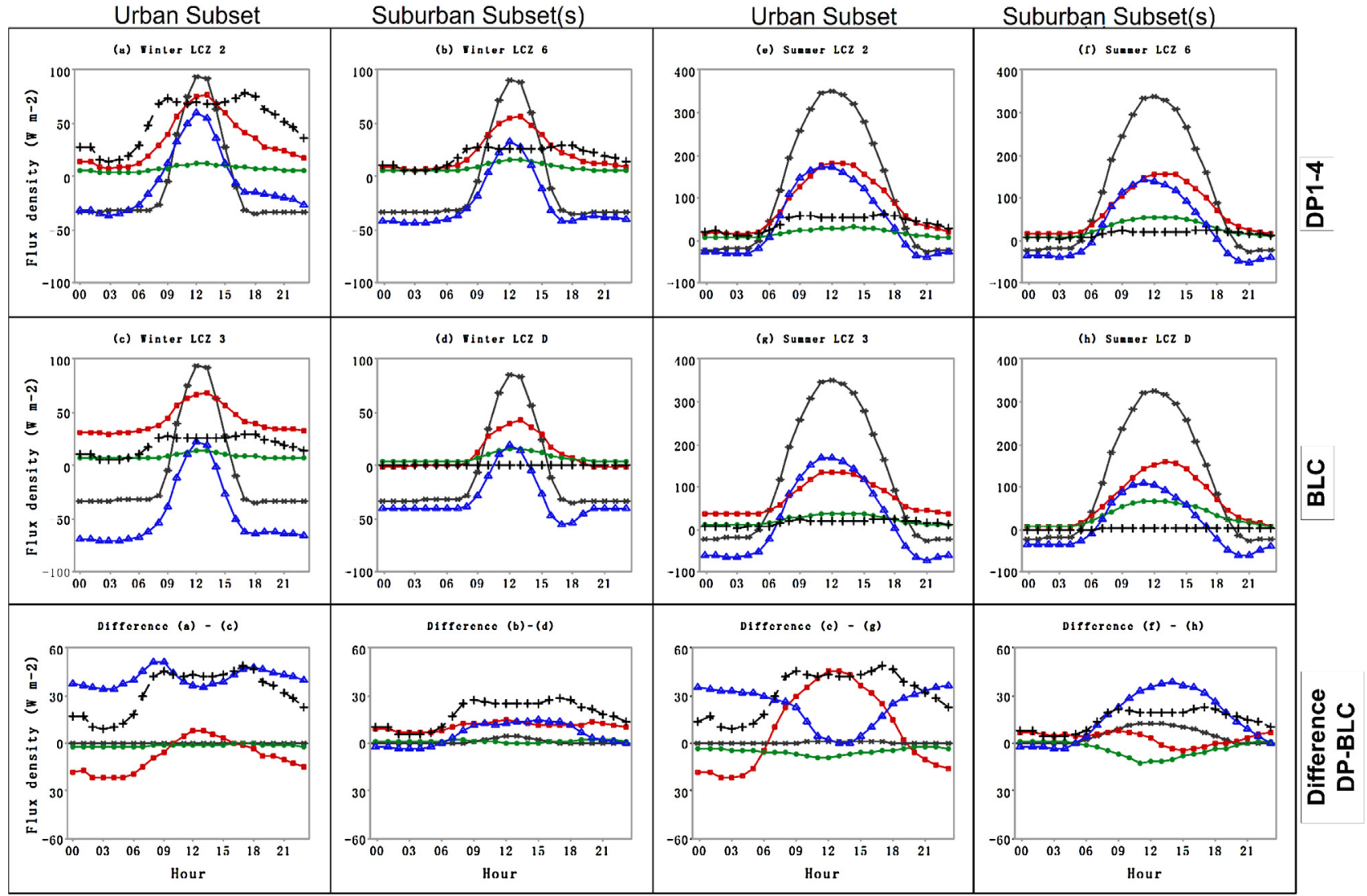

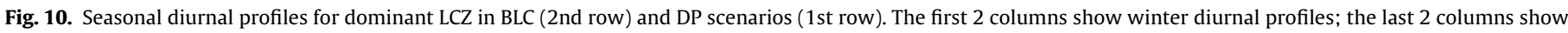

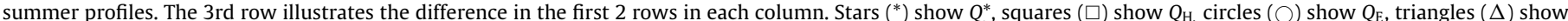

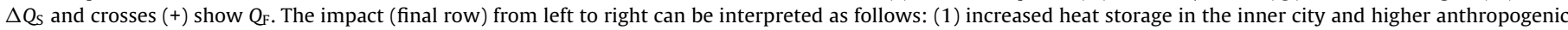

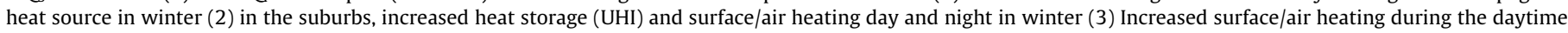
hours in the inner city during summer (4) increased heat storage and surface/air heating in summer in suburbs during summer.

\section{Discussion}

The impact of neighbourhood form and development on the urban energy budget (UEB) was examined under 4 distinct development scenarios in order to examine the optimum development pathway for Dublin city. The UEB was examined in terms of spatial changes due to urbanisation (primarily on the existing urban fringes), the seasonal differences in sensible, latent and stored heat and the impact on the diurnal profiles in different areas. Employing the local climate zone (LCZ) scheme allowed for this examination and provides useful guidance (Stewart \& Oke, 2012). However as with most urban areas, individual areas though similar in form and function will differ (i.e. intra-LCZ differences) somewhat in terms of specific fractional coverages of vegetation, buildings and pavements. The use of very high resolution data, for example individual building footprints, heights, trees derived from a LIDAR system, would have allowed for examination of the UEB in greater detail and address the limitation of treating all LCZ areas equally. However, in data starved settings for example, cities in the economically developing countries, such an approach is not feasible, therefore this approach was not employed here. Moreover, there has been a recent call for standardisation in how urban areas are described in order to allow for more robust inter-city comparisons with respect to climate, impacts on human comfort, pollution and urban development (Ching, 2013; Bechtel et al., 2015).

While the replacement of natural, vegetated landscapes with artificial materials associated with urban areas will inevitably impact upon the surface energy budget the results here illustrate that the type of urban development plays a significant role on this impact at the local scale, moreover seasonal considerations should be taken into account. The densification (i.e. upward development) of existing urban plots was shown to increase winter time storage of heat, thus reducing the level of temperature changes within these areas (sensible heat). However, this will lead to increased levels of heat released back into the atmosphere at night, which serves to enhance the urban heat island effect under the right synoptic conditions. During the summer months, daytime surface/air heat increased in these areas due to multiple reflectance (i.e. increased net radiation) which has major implications for daytime cooling requirements and human thermal comfort. Urban sprawl was shown to increase surface/air heating and heat storage significantly in both winter and summer, and decrease evapotranspiration in summer months. Again this has implications for energy use and human comfort thus strengthens the case for including such information in planning decisions. Moreover, since most of the projected development will occur along river basins, the decrease in evapotranspiration and increase in impermeability will increase runoff levels in these areas, creating a potential flood hazard. This strengthens the case for DP4 as being the DP with the lowest potential impact in terms of local climate.

The design interventions tested here focused on local scale mitigation of the impact on the UEB, undoubtedly such interventions will have a larger impact on the micro-to-building scale climate. The inclusion of coniferous vegetation in mid-latitude city such as Dublin (design intervention 1) served to reduce the seasonality of evapotranspiration which is lower in winter for deciduous vegetation (Lindberg \& Grimmond, 2011; Peng \& Jim, 2013) this in turn reduces the amplitude of surface/air heating during both win- 
Table 8

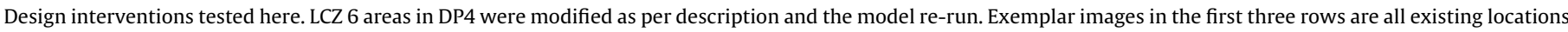
for Dublin city.
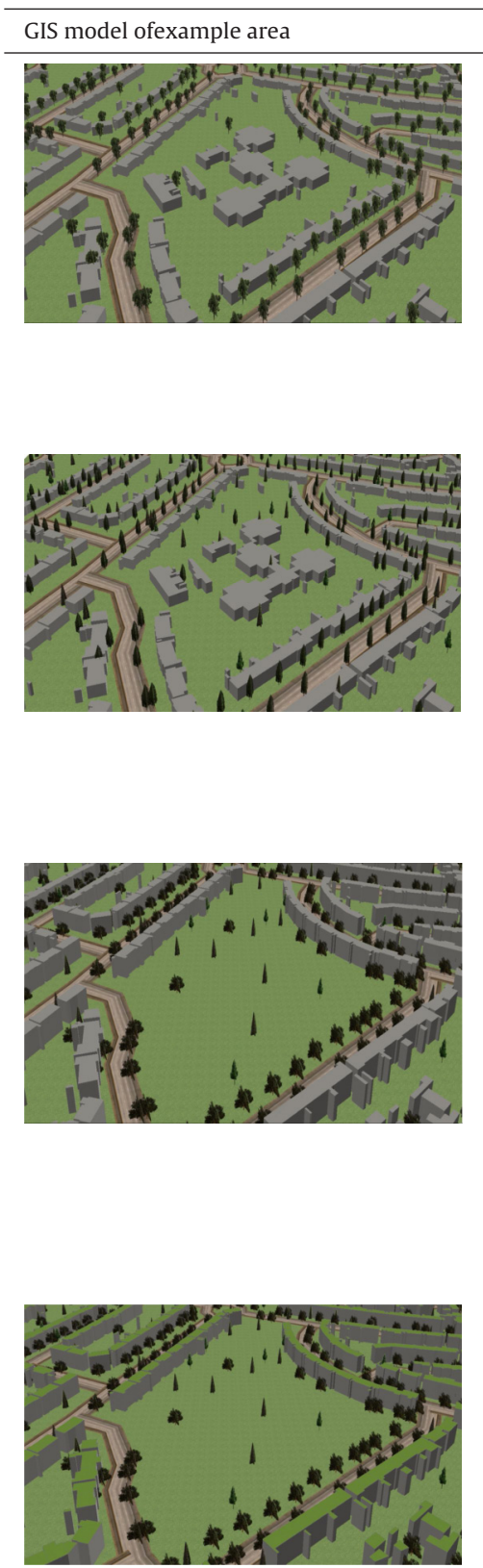
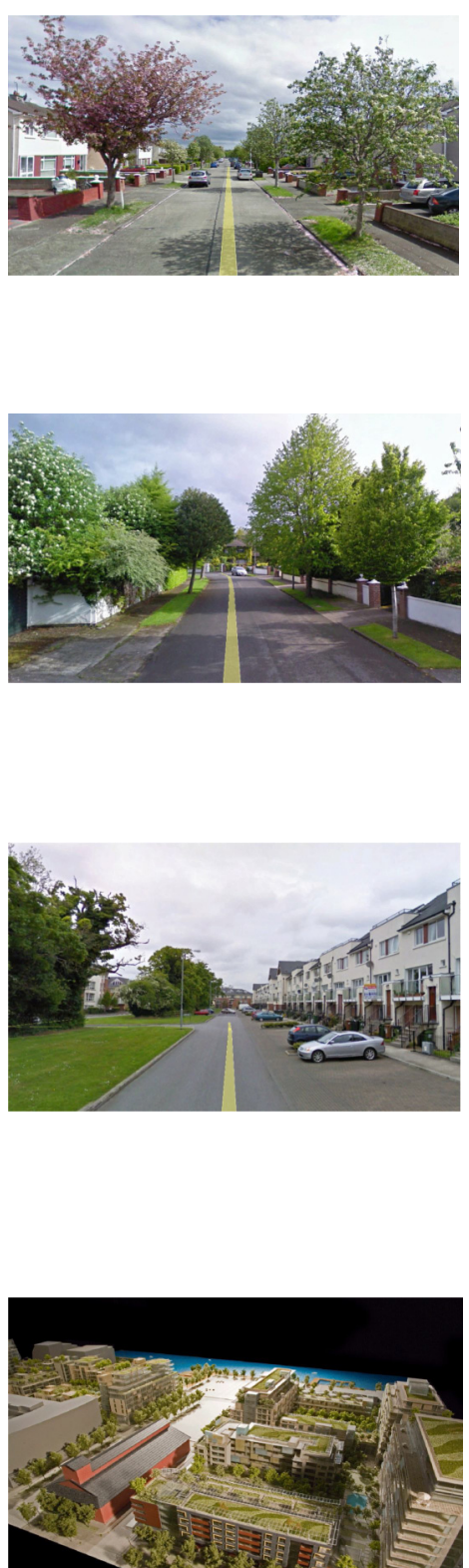

BLC area (LCZ 6)

Area comprisesLowrise buildings $(\mu=2.45 \mathrm{~m})$

$15 \%$ building cover $10 \%$ tree cover (all deciduous) and remainder split betweenpavements and unirrigated grasses
Design intervention 1 Buildings as with BLC area (above). Tree cover and unirrigated grasses are increased ( $5 \%$ each) replacing paved areas. Tree species are modified to be predominantly coniferous (80:20 split between coniferous and deciduous)
Design intervention 2

Building coverage is reduced by $5 \%$ height increased by $2.45 \mathrm{~m}$. Tree cover and unirrigated grasses are increased ( $2.5 \%$ each) replacing building areas. Trees are modified to be a mix of species (50:50 split between coniferous and deciduous)
Design intervention 3

As with design intervention 2, however

additionally green roof design is introduced to all buildings. Unirrigated vegetation type used to modify OHM coefficients for storage. Albedo and emissivity values $(\alpha, \varepsilon)$ for building roof tops also modified ter and summer months. The inclusion of green roof tops (design intervention 3 ) served to further reduce local scale partitioning of energy into both surface/air heating and heat storage which was the intended outcome. However, the decrease was similar in magnitude to the first design intervention. As such the justification for including this design feature into future planning may appear weak, however the multiple benefits of natural roofing material at different scales should also be considered and will be part of future work.

Overall the SUEWS model proved to be capable of reproducing the expected differences between urban and non-urban UEB when linked with LCZ and forced with off-site meteorological data, thus enabling background climate data to be translated into urban specific data for identifying specific areas for planning/policy interventions.

\section{Conclusion}

The aim of this study was to investigate the optimum development pathway for a mid-latitude city with respect to reducing the spatial and temporal impact on the surface energy budget. Different policy priorities informing distinct development scenarios were examined. The MOLAND cellular-automata model was linked 
with the SUEWS urban energy and water budget model, the local climate zone classification and meteorological data from outside the urban area.

Drawing from the results of this study, we conclude that the optimum development scenario is one which preserves a higher overall proportion of vegetated land cover. Such development inevitably leads to an increased proportion of energy channelled into sensible heating of the near surface atmosphere and additionally heat storage within the urban fabric across the domain.

Therefore, design interventions which aimed to reduce this impact locally were investigate. An effective solution is the inclusion of vegetation that is photosynthetically active throughout the summer months and remains active during the winter months which serves to promote energy uptake by vegetation and thus increase latent heating. We conclude that incorporating urban climate data into development and design processes where meteorological observations are otherwise absent is possible and allows for a range of development pathways and local scale impacts to be examined. Such applications serve to increase the incorporation of urban climate knowledge into the planning and design process which can ameliorate environmental conditions for the urban population and reduce the negative impacts of development.

\section{References}

Alcoforado, M. J., Andrade, H., Lopes, A., \& Vasconcelos, J. (2009). Application of climatic guidelines to urban planning: the example of Lisbon (Portugal). Landscape and Urban Planning, 90(1-2), 56-65.

Alexander, P. J., \& Mills, G. M. (2014). Local climate classification and Dublin's urban heat island. Atmoshere, 5(4), 755-774.

Alexander, P. J., Mills, G. M., \& Fealy, R. J. (2015). Using LCZ data to run an urban energy balance model. Urban Climate, 13(3), 14-37.

Balling, R. C., Cerveny, R. S., \& Idso, C. D. (2001). Does the urban $\mathrm{CO}_{2}$ dome of phoenix, arizona contribute to its heat island? Geophysical Research Letters, 28(24), 4599-4601.

Barredo, J. I., Kasanko, M. M. N., \& Lavalle, C. (2003). Modelling dynamic spatial processes: simulation of future scenarios through cellular automata. Landscape and Urban Planning, 6(3), 145-160.

Bechtel, B., Alexander, Böhner, J., Ching, J., Conrad, O., Feddema, J., et al. (2015). Mapping local climate zones for a worldwide database of the form and function of cities. ISPRS Int. J. Geo-Inf., 4(1), 199-219. http://dx.doi.org/10.3390/ ijgi4010199

Brager, G. S., \& de Dear, R. J. (1998). Thermal adaptation in the built environment: a literature review. Energy and Buildings, 27(1), 83-96.

Bramley, G., \& Power, S. (2009). Urban form and social sustainability: the role of density and housing type. Environment and Planning B: Planning and Design, 36, $30-48$

Breheny, M. J. (1991). Sustainable development and urban form. In 22nd Annual Conference of the British Section of the Regional Science Association at Mansfield College.

Brennan, M., Shahumyan, H., Walsh, C., Carty, J., Williams, B., Convery, S., et al. (2009). Regional planning guideline review: using MOLAND as part Urban Institute Ireland Working Papers Series; 09/07. pp. 1-23. Available at: http:// www.uep.ie/pdfs/WP\%200907\%20W.pdf

Bruse, M. (1999). The influences of local environmental design on microclimate-development of a prognostic numerical Model ENVI-met for the simulation of wind, temperature and humidity distribution in urban structures. $\mathrm{PhD}$ thesis: temperature and humidity distribution in urban structures. Germany: Institute of Geography, University of Bochum (in German).

CSO. (2011). Census of Ireland. Dublin: CSO Central Statistics Office of Ireland. Available online: http://www.cso.ie/en/census/ Accessed on 18.04.15

Ching, J. K. S. (2013). A perspective on urban canopy layer modeling for weather, climate and air quality applications. Urban Climate, 3(1), 13-39.

Chrysoulakis, N., Anselmo de Castro, E., \& Moors, E. (2014). Understanding urban metabolism: a tool for urban planning. London, United Kingdom: Routledge (Taylor and Francis).

Chrysoulakis, N., et al. (2013). Sustainable urban metabolism as a link between bio-physical sciences and urban planning: The BRIDGE project. Landscape and Urban Planning, 112(0), 100-117.

Couclelis, H. (2005). Where has the future gone? Rethinking the role of integrated land-use models in spatial planning. Environment and Planning A, 37(8), 1353-1371.

Demuzere, M., Oleson, K., Coutts, A. M., Pigeon, G., \& van Lipzig, N. P. M. (2013). Simulating the surface energy balance over two contrasting urban environments using the community land model urban. International Journal of Climatology, 33(15), 3182-3205.

Eliasson, I. (2000). The use of climate knowledge in urban planning. Landscape and Urban Planning, 48(1-2), 31-44.
Elkin, T., McLaren, D., \& Hillman, M. (1991). Reviving the city: towards sustainable urban environment. London: Friends of the Earth.

Flanner, M. G. (2009). Integrating anthropogenic heat flux with global climate models. Geophysical Research Letters, 36(2).

Gál, T., \& Unger, J. (2009). Detection of ventilation paths using high-resolution roughness parameter mapping in a large urban area. Building and Environment, 44(1), 198-206.

Getis, A., \& Ord, J. K. (1992). The analysis of spatial association by use of distance statistics. Geographical Analysis, 24(3), 189-206.

Givoni, B. (1992). Comfort, climate analysis and building design guidelines. Energy and Buildings, 18(1), 11-23.

Goldberg, V., Kurbjuhn, C., \& Bernhofer, C. (2013). How relevant is urban planning for the thermal comfort of pedestrians? Numberical case studies in two districts of the City of Dresden (Saxony/Germany). Meteorologische Zeitschrift, 22(6), 739-751.

Graham, E. (1993). The urban heat Island of Dublin City during the summer months. Irish Geography, 26(1), 45-57.

Gray, K. A., \& Finster, M. E. (2000). The urban heat island, photochemical smog, and Chicago: local features and the problem and solution. Evanston, IL: Northeastern University.

Grimmond, C. S. B., Blackett, M., Best, M. J., Baik, J.-J., Belcher, S. E., Beringer, J., et al. (2011). Initial results from Phase 2 of the international urban energy balance model comparison. International Journal of Climatology, 31(2), 244-272.

Grimmond, C. S. B., Blackett, M., Best, M. J., Barlow, J., Baik, J.-J., Belcher, S. E., et al. (2010). The international urban energy balance models comparison project: first results from Phase 1. Journal of Applied Meteorology and Climatology, 49(6), 1268-1292.

Grimmond, C. S. B., \& Oke, T. R. (1995). Comparison of heat fluxes from summertime observations in the suburbs of four North American Cities. Journal of Applied Meteorology, 34(4), 873-889.

Grimmond, C. S. B., \& Oke, T. R. (2002). Turbulent heat fluxes in urban areas: observations and a local-scale urban meteorological parameterization scheme (LUMPS). Journal of Applied Meteorology, 41(7), 792-810.

Hebbert, M., \& Mackillop, F. (2013). Urban climatology applied to urban planning: a postwar knowledge circulation failure. International Journal of Urban and Regional Research, 37(5), 1542-1558.

Idsoa, C. D., Idso, S. B., \& Balling, R. C. (1998). The urban $\mathrm{CO}_{2}$ dome of Phoenix, Arizona. Physical Geography, 19(2), 95-108.

IPCC. (2014). Human settlements, infrastructure and spatial planning. In Climate change 2014: mitigation of climate change. contribution of working group III to the fifth assessment report of the intergovernmental panel on climate change. Cambridge, United Kingdom and New York, NY, USA: Cambridge University Press.

Järvi, L., Grimmond, C. S. B., Taka, M., Nordbo, A., Setälä, H., \& Strachan, I. B. (2014). Development of the surface urban energy and water balance scheme (SUEWS) for cold climate cities. Geoscientific Model Development, 7(4), 1691-1711.

Järvi, L., Grimmond, C. S. B., \& Christen, A. (2011). The surface urban energy and water balance scheme (SUEWS): evaluation in Los Angeles and vancouver. Journal of Hydrology, 411(3-4), 219-237.

Jorgenson, A. K., \& Rice, J. (2010). Urban slum growth and human health: a panel study of infant and child mortality in less-developed countries 1990-2005. Journal of Poverty, 14(4), 382-402.

Karl, T. R., Diaz, H. F., \& Kukla, G. (1988). Urbanization: its detection and effect in the United States climate record. Journal of Climate, 1(11), 1099-1123.

Keogh, S., Mills, G. M., \& Fealy, R. J. (2012). The energy budget of the urban surface: two locations in Dublin. Irish Geography, 4(1), 1-23.

Krayenhoff, E. S., \& Voogt, J. A. (2007). A microscale three-dimensional urban energy balance model for studying surface temperatures. Boundary-Layer Meteorology, 123(3), 433-461.

Kusaka, H., Kondo, H., Kikegawa, Y., \& Kimura, F. (2001). A simple single-layer urban canopy model for atmospheric models: comparison with multi-layer and slab models. Boundary-Layer Meteorology, 101(3), 329-358.

Lemonsu, A., Kounkou-Arnaud, R., Desplat, J., Salagnac, J. L., \& Masson, V. (2013). Evolution of the Parisian urban climate under a global changing climate. Climatic Change, 116(3-4), 679-692.

Levlovics, E., Gál, T., \& Unger, J. (2013). Mapping local climate zones with a vector-based GIS method. AERPA Conference, 230-423. Available at (http:// aerapa.conference.ubbcluj.ro/2013/pdf/53\%20lelovics\%20et\%20al\%20423_430. pdf)

Lin, C.-Y., Chen, F., Huang, J. C., Chen, W.-C., Liou, Y.-A., Chen, W.-N., et al. (2008). Urban Heat Island effect and its impact on boundary layer development and land-sea circulation over northern Taiwan. Atmospheric Environment, 42(22), 5635-5649.

Lindberg, F., \& Grimmond, C. S. B. (2011). The influence of vegetation and building morphology on shadow patterns and mean radiant temperatures in urban areas: model development and evaluation. Theoretical and Applied Climatology, 105(3-4), 311-323.

Lindberg, F., Holmer, B., \& Thorsson, S. (2008). SOLWEIG 1.0-modelling spatia variations of 3D radiant fluxes and mean radiant temperature in complex urban settings. International Journal of Biometeorology, 52(7), 697-713.

Marland, G., et al. (2003). The climatic impacts of land surface change and carbon management, and the implications for climate-change mitigation policy. Climate Policy, 3(2), 149-157.

Martine, G., McGranahan, G., Montgomery, M., \& Fernández-Castillia, R. (2008). The new global frontier: urbanization, poverty and environmental in the 21st century (1st ed.). London: Earrthscan (Routledge). 
Masson, V. (2000). A physically-based scheme for the urban energy budget in atmospheric models. Boundary-Layer Meteorology, 94(3), 357-397.

Middel, A., Häb, K., Brazel, A. J., Martin, C. A., \& Guhathakurta, S. (2014). Impact of urban form and design on mid-afternoon microclimate in Phoenix local climate zones. Landscape and Urban Planning, 122, 16-28.

Mills, G. M. (2007). Cities as agents of global change. International Journal of Climatology, 27(14), 1849-1857.

Mills, G. M. (2008). Urban climatology and its relevance to urban design. In PLEA 2008 25th Conference on Passive and Low Energy Architecture. http:// architecture.ucd.ie/Paul/PLEA2008/content/papers/oral/PLEA_FinalPaper_ref 250.pdf, Accessed 24.04.15

Mills, G. M., Cleugh, H., Emmanuel, R., Endlicher, W., Erell, E., McGranahan, G., et al (2010). Climate information for improved planning and management of mega cities (needs perspective). Procedia Environmental Sciences, 1(1), 228-246.

Moussiopoulos, N., Sahm, P., \& Kessler, C. H. (1995). Numerical simulation of photochemical smog formation in Athens, Greece-a case study. Atmospheric Environment, 29(24), 3619-3632.

Niehoff, D., Fritsch, U., \& Bronstert, A. (2002). Land-use impacts on storm-runoff generation: scenarios of land-use change and simulation of hydrological response in a meso-scale catchment in SW-Germany. Journal of Hydrology, 267(1-2), 80-93.

Offerle, B., Grimmond, C. S. B., \& Fortuniak, K. (2005). Heat storage and anthropogenic heat flux in relation to the energy balance of a central European city centre. International Journal of Climatology, 25(10), 1405-1419.

Oke, T. R. (1984). Towards a prescription for the greater use of climatic principles in settlement planning. Energy and Buildings, 7(1), 1-10.

Ord, J. K., \& Getis, A. (1995). Local spatial autocorrelation statistics: distributional issues and an application. Geographical Analysis, 27(4), 286-306.

Patz, J., Campbell-Lendrum, D., Holloway, T., \& Foley, J. A. (2005). Impact of regional climate change on human health. Nature, 438, 310-317.

Peng, L. L. H., \& Jim, C. Y. (2013). Green-roof effects on neighborhood microclimate and human thermal sensation. Energies, 6(2), 598-618.

Picone, N., \& Campo, A. M. (2015). Preparing urban climate maps using Local Climate Zones (LCZ) methodology to improve communication with urban planners: the case of Tandil city, Argentina. In 9th International Conference on Urban Climate (ICUC9) Proceedings, TUKUP6: Indicators and climate maps II: urban planning.

Schlünzen, K. H., Grawe, D., Bohnenstengel, S. I., Schlüter, I., Koppmann, R., et al. (2011). Joint modelling of obstacle induced and mesoscale changes-current limits and challenges. Journal of Wind Engineering and Industrial Aerodynamics, 99, 217-225.

Schlünzen, K. H., Hinneburg, D., Knoth, O., Lambrecht, M., Leitl, B., López, S., et al. (2003). Flow and transport in the obstacle layer: first results of the micro-scale model MITRAS. Journal of Atmospheric Chemistry, 44(2), 113-130.
Shaviv, E. (1984). Climate and building design-tradition, research and design tools. Energy and Buildings, 7(1), 55-69.

Stewart, I. D., \& Oke, T. R. (2012). Local climate zones for urban temperatures. Bulletin of the American Meteorological Society, 1879-1900.

Stewart, I. D., Oke, T. R., \& Krayenhoff, E. S. (2014). Evaluation of the 'local climate zone' scheme using temperature observations and model simulations. International Journal of Climatology, 34(4), 1062-1080.

Svensson, M. K., \& Eliasson, I. (2002). Diurnal air temperatures in built-up areas in relation to urban planning. Landscape and Urban Planning, 61(1), 37-57.

Sweeney, J. (1987). The urban heat island of Dublin City. Irish Geography, 20(1), $1-10$.

UN. (2014). World urbanization prospects the 2014 revision. New York: United Nations. ISBN 978-92-1-151517-6.

Van de Voorde, T., van der Kwast, J., Poelmans, L., Canters, F., Binard, M., Cornet, Y., et al. (2016). Projecting alternative urban growth patterns: the development and application of a remote sensing assisted calibration framework for the Greater Dublin Area. Ecological Indicators, 60, 1056-1069.

Veldkamp, A., \& Fresco, L. O. (1997). Exploring land use scenarios, an alternative approach based on actual land use. Agricultural Systems, 55(1), 1-17.

Walsh, S. (2014). Annual summary 2014. Climate report. Dublin: Climatology and Observations Division Met Éireann-Irish Meteorological Service.

Wang, X. M., Lin, W. S., Yang, L. M., Deng, R. R., \& Lin, H. (2007). A numerical study of influences of urban land-use change on ozone distribution over the Pearl River Delta Region, China. Tellus B: Chemical and Physical Meteorology, 59(3) 633-641.

Ward, I. C. (2003). The usefulness of climatic maps of built-up areas in determining drivers for the energy and environmental efficiency of buildings and external areas. International Journal of Ventilation, 2(3), 277-286.

Ward, H. C., Evans, J. G., \& Grimmond, C. S. B. (2014). Multi-scale sensible heat fluxes in the suburban environment from large-aperture scintillometry and eddy covariance. Boundary-Layer Meteorology, 152(1), 65-89.

Williams, B., Shahumyan, H., Boyle, I., Convery, S., \& White, R. (2012). Utilizing an urban-regional model (MOLAND) for testing the planning and provision of wastewater treatment capacity in the Dublin Region 2006-2026. Planning Practice E' Research, 27(2), 227-248.

Xiang, W.-N., \& Clarke, K. C. (2003). The use of scenarios in land-use planning. Environment and Planning B: Planning and Design, 30, 885-909.

Yaghoobian, N., Kleissl, J., \& Krayenhoff, E. S. (2010). Modeling the thermal effects of artificial turf on the urban environment. Journal of Applied Meteorology and Climatology, 49(3), 332-345. 